\title{
Risk Reporting and Bank Runs
}

\author{
Susanne Homölle \\ Institut für Kreditwesen \\ Westfälische Wilhelms-Universität Münster \\ Universitätsstraße 14-16 \\ 48143 Münster, Germany \\ Phone: +49-251-8322879 \\ Fax: $+49-251-8322882$ \\ E-mail: 21suth@wiwi.uni-muenster.de
}

July 7, 2003

\begin{abstract}
Increasing risk disclosure of banks, e.g. via risk reporting in their annual accounts, is high on the agenda. In this paper, we analyse whether risk reporting of banks only shows favourable effects as supposed by regulatory authorities or whether there exist undesired effects as well. Referring to the literature on deposit contracts and bank runs, we concentrate on the impact on depositors' withdrawal decisions and banks' asset risk. Risk reporting does not generally lead to a decrease in banks' risk exposure and the probability of bank runs, respectively. Instead it induces higher risk exposure under certain conditions, which are identified in this paper.
\end{abstract}




\section{Introduction}

Since the implementation of the Law on Corporate Control and Transparency (KonTraG) in 1998, German banks have to report on their risk in their annual reports (see $\S \S 289$ I, 315 I German Commercial Code (HGB)). This rule is supplemented by the German Accounting Standards GAS 5 "Risk Reporting" and GAS 5-10 "Risk Reporting of Banks", which has been the first accounting standard worldwide that regulates risk reporting in a comprehensive manner. Moreover, bank regulators promote enhanced transparency to support market discipline as a new, complementary element of bank regulation (see, e.g., the third pillar of Basel II). As one of the relevant regulatory requirements, increased risk dislosure should help to restrict banks' risk-taking.

In this paper, we analyse whether risk reporting of banks only shows favourable effects as supposed by the regulatory authorities or whether there exist some undesired effects as well. Hirshleifer (1971) has already shown that additional information does not have to be beneficial but may lead to negative consequences. The purpose of this paper is to analyse the effects of a special kind of information, namely information about risk and especially the risk reporting of banks. As deposits are typical of banks, we concentrate on the depositors' reactions: How are the depositors' decisions to withdraw their money or to keep it in the bank influenced by the bank's risk reporting? Additionally, we look at the reaction of the bank to possible changes in the depositors' behaviour.

There is only little literature on the effects of risk reporting. Some empirical work on capital markets reactions to risk disclosure is done by Rajgopal (1999), Linsmeier et al. (2000), Rajgopal and Venkatachalam (1999), and Thornton and Welker (2000), but they do not consider banks. The only paper comparable to ours is the analytical work of Cordella and Levy Yeyati (1998). They show that risk disclosure may increase the ex ante probability of bank insolvency. However, they use some quite restrictive assumptions as uniformly distributed asset returns, and even more importantly, they do not model the characteristics of deposits. In this paper we choose a more general framework insofar as we abstract from a special distribution over asset returns. At the same time we are more specific including main features of deposits, thereby trying to combine accounting theory and the theory of financial intermediation.

Our work is related to the literature on deposit contracts and bank runs. Referring to the seminal paper of Diamond and Dybvig (1983) we model a bank that takes deposits from depositors with different time preferences for consumption but cannot observe these preferences and invests its total funds in illiquid assets. However, this basic model is extended 
in several aspects. Firstly, we consider risky assets. Chari and Jagannathan (1988) and Jacklin and Bhattacharya (1988) were among the first who assumed risky assets to derive so-called information-based bank runs, i.e. bank runs that were driven by (asymmetrically distributed) information about asset returns. In the models with ex ante risky assets it is usually assumed that the depositors receive a signal (sometimes with noise) on the true value of asset returns before they make their withdrawal decisions. ${ }^{1}$ In this paper, however, uncertainty is not resolved before the end of the planning period, i. e. not before asset returns are actually paid. Instead the depositors receive some interim information about asset risk as the bank reports on the values of selected downside risk measures. We show that the expected shortfall (Lower Partial Moment One, $L P M_{1}$ ) and the target semivariance (Lower Partial Moment Two, $L P M_{2}$ ) are the risk measures relevant for the depositors' withdrawal decisions.

Secondly, we introduce shareholders to model the characteristics of banks and their deposits. $^{2}$ The depositors are no longer residual claimants but get a fixed return provided that the bank does not go bankrupt. Excess returns are paid to the shareholders. Equity is assumed to be just so high that pure panic runs as described by Diamond and Dybvig (1983) will not occur. So we can concentrate on bank runs that are based on the bank's risk reporting or the depositors' expectation concerning asset risk.

Thirdly and most importantly, the purposes are different. Diamond and Dybvig (1983) and the subsequent papers that show variations of their basic model intend to derive a deposit contract that optimises risk sharing between depositors. In our paper, however, a standard deposit contract is by assumption exogenously given to concentrate on (the change in) depositors' withdrawal decisions due to risk reporting.

We start our analysis with the analytical more convenient case of risk reporting. The bank discloses information on its risk exposure and at the same time has to decide whether to adjust the return on deposits, e.g. to prevent a bank run. This scenario is compared with a scenario without risk reporting where a game of incomplete information between bank

1 In Allen and Gale (1998) and Drehmann (2002), e.g., all depositors know the true value of asset returns before they make their withdrawal decisions. Carletti (1999), Chari and Jagannathan (1988), Chen (1999), Gorton and Pennacchi (1990), Jacklin (1989), and Jacklin (1993) assume that at least a fraction of depositors is perfectly informed. A signal with noise is modelled by Boonprakaikawe and Ghosal (2001), Dasgupta (2001), Goldstein and Pauzner (2002), Gorton (1985), and Rochet and Vives (2002). In Alonso (1996), Bougheas (1999), Calomiris and Kahn (1991), Chen (1994), Jacklin and Bhattacharya (1988), Loewy (1998), and Wolf (1999) the depositors update the discrete probability distribution over asset returns. However, the random returns may only take two values. Continuous distribution functions and risk measures other than the probability of the low return are not considered.

2 As Dowd (1992), p. 112, put it, the demand deposits of Diamond and Dybvig (1983) are "a kind of debt-equity hybrid" because the depositors who leave their deposits in the bank until the final period only get a residual payment. The intermediary is "more like a mutual fund than a bank". 
and depositors has to be analysed. In this game different kinds of equilibria are possible depending on the parameters of the model. On the one hand, pooling equilibria may be observed, in which an "average" return on deposits is agreed upon regardless of the bank's asset risk. No bank run will occur. On the other hand, equilibria with adverse selection may exist: Only in case of high asset risk, the bank offers an adequate return on deposits. Otherwise, it will leave the market.

Provided that without risk reporting there exists a pooling equilibrium, risk reporting leads to higher asset risk of rather risky types of banks (or to a bank run on these banks) while reducing the risk of a bank with already quite low asset risk. If, however, in case of no risk reporting only the riskiest types of banks offer a return on deposits so that the deposits are not withdrawn, risk reporting may help to prevent this adverse selection. According to these results, risk reporting does not generally decrease banks' risk exposure or lessen the probability of bank runs, but may lead to an increase in insolvency risk of risky banks. Such an ex post increase in the risk exposure of a rather risky bank is the more likely, the less risk averse the depositors, the smaller the return on assets in case of early liquidation, the higher the a priori probability of low asset risk, and the smaller the range of possible levels of asset risk. We also derive conditions under which a bank's risk exposure in case of risk reporting is ex ante higher than in the scenario without risk reporting.

The paper is organised as follows: In Section 2 we introduce the basic assumptions and

time structure of our model. Section 3 shows the equilibrium behaviour of the bank and its depositors if the bank reports on its asset risk. The equilibrium behaviour in the benchmark scenario without risk reporting is analysed in Section 4. In Section 5 the results of both scenarios are compared to derive the effects of risk reporting. Section 6 provides a summary and outlook.

\section{The Model}

\section{Basic Assumptions}

Risk reporting of a monopolistic bank, which holds deposits and equity, is analysed in a three period model with $T=0,1,2$. In period $T=0$ each depositor is endowed with one dollar. We assume a continuum of unit mass of ex ante identical, risk averse depositors. The utility function $u(\cdot)$ is strictly increasing and strictly concave and equals (or may at least be approximated by) a second-degree polynomial. According to Diamond and Dybvig (1983) 
there exist two types of depositors. Type $1(2)$ wants to consume at $T=1(T=2) \cdot{ }^{3}$ In period $T=1$ each depositor learns his type only. However, the fraction of type $1, t \in(0,1)$, and thus the a priori probability of being type 1 are publicly known at $T=0$. For each dollar deposited the bank promises to pay $d_{1}\left(d_{2}\right)$ provided that the depositor withdraws at $T=1(T=2)$. The deposit contract agreed upon at $T=0$ is exogenously given with

$$
1<d_{1}<d_{2}=d_{2}^{v} \cdot
$$

With $d_{1}>1$ the depositors of type 1 obtain more than the invested dollar. If $d_{1} \geq d_{2}$, the depositors of type 2 would in any case withdraw their money at $T=1$ and store it privately until $T=2$. Depositors' decisions would be independent of any (risk) information about the bank and hence trivial. The deposit contract is neither contingent on depositors' type, which is not publicly observable, nor on bank's risk. Moreover, the depositors can withdraw their deposits at any time. Thus we use a standard (demand) deposit contract. ${ }^{5}$ In compensation for the depositors' right to withdraw at any time, the bank has got the option to change the promised return $d_{2}$ at $T=1 .^{6}$ With this option we take into account another important feature of demand deposit contracts.

To model the characteristics of banks, the bank does not only issue deposits but also raises equity, $C$, at $T=0$. In reality, banks have to raise a certain amount of equity to receive the bank charter thus being able to issue deposits. Moreover, there exist regulatory restrictions such as Basel I or II that require a minimum amount of equity to hold risky assets. The risk neutral shareholders have limited liability. They are the residual claimants. In non-bankruptcy states at $T=2$ the shareholders get the bank's final net worth whereas the depositors obtain a fixed repayment of their deposits, which is $d_{2}$ (per depositor). The shareholders know for sure that they will consume at $T=2$. The bank's equity, $C$, cannot be increased or reduced until $T=2$. The shareholders and bank managers are identical so that agency conflicts between bank (owners) and managers are excluded. ${ }^{7}$

At $T=0$ the bank invests its total funds in risky, illiquid assets. The random return at

3 Dowd (1992), Drehmann (2002), Gorton and Pennacchi (1990), and Hellwig (1994), also assume corner preferences.

4 See also Drehmann (2002) and Rochet and Vives (2002), who take the deposit contracts as given and analyse depositors' withdrawal decisions. The deposit contract shows similar properties than the optimal deposit contract of Diamond and Dybvig (1983). In case of riskless asset returns, they derive the optimal deposit contract with $1<d_{1}<d_{2}<R$.

5 "The typical deposit contract is 'noncontingent", Allen and Gale (1998), p. 1256.

$6 \quad$ Notice that $d_{2}$ is a variable in our model. The symbol $d_{2}^{v}$ is used if we refer to the level of $d_{2}$ agreed upon in $T=0$.

7 For the assumptions concerning bank shareholders see also Dowd (1992), p. 124 f., and Wolf (1999), p. 274-279. Rochet and Vives (2002) also introduce shareholders in their analysis of the depositors' withdrawal decisions but do not further characterise these shareholders. They state rightly that "a proper modeling of the role of equityholders remains to be done", Rochet and Vives (2002), p. 12. 
$T=2$ (per invested dollar), $R$, is continuously distributed over the interval $[0, \bar{R}]$ and not known before realisation at $T=2$. If assets are liquidated at $T=1$, they earn a riskless but rather low return (per invested dollar) of $r \in(0,1]$. In period $T=1$ the bank knows the expected return, $E[R]>1$, and always reports on this value. With this assumption we isolate the impact of risk reporting on depositors' behaviour from the impact of information about expected returns. At $T=1$, the bank also obtains information about asset risk. It knows the (continuous) distribution function over asset returns, $F(R)$, and hence the Lower Partial Moments, $\operatorname{LPM}_{i}(\cdot)$, for a given target, $R^{k} \in[0, \bar{R}]$. They are defined as follows:

$$
\operatorname{LPM}_{i}\left(R^{k}\right) \equiv \int_{0}^{R^{k}}\left(R^{k}-R\right)^{i} d F(R), \quad i=0,1,2, \ldots
$$

Without risk reporting the depositors cannot observe asset risk.

For analytical convenience, we assume that all but one parameters of the distribution function are common knowledge. ${ }^{8}$ Moreover, common priors are assumed, i. e. the bank and its depositors know the a priori probability of the unknown parameter $\theta, p(\theta)$, and the set of all possible values of $\theta, \Theta$. At $T=1$ the bank is informed about $\theta$. In this paper risk reporting means that the bank reports on the expected shortfall, $L P M_{1}\left(R^{k}\right)$, and the target semivariance, $L P M_{2}\left(R^{k}\right) .{ }^{9}$ Both are a function of the target $R^{k}$ as well as of $\theta . L P M_{1}\left(R^{k}\right)$ is positively related to $\theta$ :

$$
\frac{\partial L P M_{1}\left(R^{k}\right)}{\partial \theta} \geq 0 \quad \forall R^{k} \in[0, \bar{R}]
$$

where the inequality holds strictly for at least some values of $R^{k}$. The maximum of $\theta, \bar{\theta} \in \Theta$, characterises maximum risk insofar as, for a given $R^{k}, L P M_{1}\left(R^{k}\right)$ reaches its maximum.

\section{Time Structure}

The time structure of our model is as follows (see also Figure 1, p. 31): In period $T=0$ the bank is founded by the shareholders. Depositors place their money in the bank. Total capital is invested in risky assets. As we concentrate on a bank with deposit contracts that already exist, the decisions in period $T=0$ are taken as given. Instead we look at the behaviour of the bank and its depositors in the following period.

In period $T=1$ nature chooses asset risk, which is observed by the bank. Alternatively we consider two scenarios: In the first scenario the bank truly reports on asset risk, e. g. to

\footnotetext{
8 Notice that the expected return, $E[R]$, cannot be the unknown parameter because $E[R]$ is common knowledge at $T=1$.

$9 \quad$ Below we define $R^{k}$ and show that the risk measures relevant for the depositors' withdrawal decision are indeed $L P M_{1}\left(R^{k}\right)$ and $L P M_{2}\left(R^{k}\right)$.
} 
comply with regulatory restrictions. In the benchmark scenario the bank does not disclose asset risk so that there exists a game of incomplete information between bank and depositors, which, however, can be transformed into a game of imperfect information (Harsanyi, 1967/8). Depending on asset risk, different types of banks are distinguished.

In both scenarios the bank informs about the expected value of asset returns. Moreover, the bank may offer an adjustment of the return on deposits, $d_{2}$. The bank has to decide how to change $d_{2}$ to maximise its expexted net worth at $T=2$. The support of $d_{2}$ is $\mathcal{D}=\left[d_{1}, \bar{R} d_{1} / r\right]$. The bank will only offer an adjustment of $d_{2}$ if it improves the expected final net worth. Otherwise it refrains from changing $d_{2}$.

Each depositor learns his type at $T=1$. Type 1 withdraws his deposit to consume at $T=1$. The bank liquidates assets to repay deposits. Type 2 has to decide whether to withdraw at $T=1$ as well (and store the money privately until $T=2$ ) or to wait until $T=2$. If the bank offers an adjustment of $d_{2}$, the depositors of type 2 can accept this offer or withdraw their deposits.

Type 2's withdrawal decision is influenced by the question whether the bank may be liquid or illiquid at the end of period $T=1$. The bank is still liquid at the end of period $T=1$ and can continue its business in period $T=2$ if the liquidation value of assets exceeds the promised returns on the deposits withdrawn:

$$
r(C+D)>w d_{1} D \quad \Leftrightarrow \quad C+\left(1-\frac{w d_{1}}{r}\right) D>0
$$

where $D$ is the amount of deposits and $w \in[t, 1]$ the fraction of depositors who withdraw at $T=1$. The right-hand inequality shows the (positive) amount of assets at the end of period $T=1$.

The fear of the bank's illiquidity caused by too many deposits withdrawn at $T=1$ is the main reason why panic runs (Diamond and Dybvig, 1983) may exist. To concentrate on information-based bank runs we rule out the possibility of panic runs by assuming that equity is just so high or the debt-to-equity ratio is so low that the bank can repay all deposits $(w=1)$ in period $T=1$ :

$$
r(C+D)=d_{1} D \quad \Leftrightarrow \quad \frac{D}{C}=\frac{r}{d_{1}-r} .
$$

With (2) the assets at the end of period $T=1$ simplify to

$$
C+\left(1-\frac{w d_{1}}{r}\right) D=(1-w) \frac{d_{1}}{r} D
$$


In period $T=2$ the returns on these assets are realised. The depositors who have not withdrawn early obtain the promised return, $d_{2}$, provided the bank is solvent. The shareholders receive the bank's final net worth. The bank is solvent at $T=2$ if the returns on assets that were not liquidated at $T=1$ are at least as high as the promised returns on deposits not yet withdrawn:

$$
R(1-w) \frac{d_{1}}{r} D \geq(1-w) d_{2} D
$$

Referring to the sign of equality in (3), the return critical for bank solvency at $T=2$ is defined as

$$
R^{k} \equiv \begin{cases}\frac{d_{2} r}{d_{1}} & \text { for } \quad t \leq w<1 \\ \bar{R}+\epsilon, \epsilon>0 & \text { for } \quad w=1\end{cases}
$$

Only if $R \geq R^{k}$, the bank can pay the promised return $d_{2}$. Otherwise it is insolvent at $T=2 .{ }^{10}$ Asset returns are proportionally distributed among depositors. Each depositor gets

$$
R \frac{(1-w) \frac{d_{1}}{r} D}{(1-w) D}=R \frac{d_{1}}{r}, \quad w<1
$$

If $w=1$, the bank goes into liquidation at the end of period $T=1$ and thus, by definition, is insolvent at $T=2$ as well $\left(R<R^{k}=\bar{R}+\epsilon \forall R \in[0, \bar{R}]\right)$.

\section{Equilibrium Behaviour With Risk Reporting}

In this section we have a closer look at bank behaviour and depositors' decisions ${ }^{11}$ at $T=1$. The bank learns its asset risk. It gets information about the value of $\theta$ thus knowing $L P M_{1}(\cdot)$ and $L_{P} M_{2}(\cdot)$ and reports on the values of these downside risk measures. Besides, it has to decide whether to offer an adjustment of the promised return on deposits, $d_{2}$, anticipating the depositors' reactions to such an adjustment and to the risk disclosure.

A depositor who decides whether to withdraw at $T=1$ knows that, according to (2), the bank can pay out all depositors at $T=1$. Therefore, it will not be illiquid as long as the depositor himself keeps his deposit in the bank. Even if all other depositors withdrew

10 We use the terms "illiquidity" and "insolvency" to clarify whether the bank fails in period $T=1$ or $T=2$. The bank is called illiquid if there are too many depositors who want to withdraw their deposits at $T=1$. A bank is insolvent if asset returns at $T=2$ are too low compared with the bank's liabilities.

11 As type 1 withdraws at $T=1$ regardless of any information about asset risk, we restrict our analysis to the behaviour of type 2 depositors and call them simply "depositors". 
their money, the depositor would get $d_{1}$ if he withdrew as well. For this reason the return on deposits at $T=1$ is riskless whereas the return at $T=2$ is still risky. The depositor waits until $T=2$ if the expected utility of the return at $T=2$ is at least as high as the utility of $d_{1}:{ }^{12}$

$$
E\left[u\left(\min \left\{d_{2}, R \frac{d_{1}}{r}\right\}\right)\right]=\int_{0}^{R^{k}} u\left(R \frac{d_{1}}{r}\right) d F(R)+\int_{R^{k}}^{\bar{R}} u\left(d_{2}\right) d F(R) \geq u\left(d_{1}\right) .
$$

The depositors' decisions are independent of $w$ and thus of the behaviour of other depositors. The depositors follow dominant strategies.

Using integration by parts the expected utility of the return at $T=2$ can be transformed into (see appendix A.1, p. 21)

$$
\begin{aligned}
E\left[u\left(\min \left\{d_{2}, R \frac{d_{1}}{r}\right\}\right)\right]= & u\left(d_{2}\right)+\sum_{i=1}^{n-1} \frac{1}{i !}\left(-\frac{d_{1}}{r}\right)^{i} u^{(i)}\left(d_{2}\right) L P M_{i}\left(R^{k}\right) \\
& +\left(-\frac{d_{1}}{r}\right)^{n} \int_{0}^{R^{k}} u^{(n)}\left(R \frac{d_{1}}{r}\right) d F^{[n]}(R)
\end{aligned}
$$

where $F^{[n]}(\cdot)$ results from integrating $F(\cdot) n$ times. $u^{(i)}(\cdot)$ symbolises the $i$ th derivative of the utility function. Since we assume that the utility function may at least be approximated by a second-degree polynomial, condition (4) can be rewritten as

$$
\Delta^{m}\left(d_{2}\right)=u\left(d_{2}\right)-\frac{d_{1}}{r} u^{(1)}\left(d_{2}\right) L P M_{1}\left(R^{k}\right)+\frac{d_{1}^{2}}{2 r^{2}} u^{(2)}\left(d_{2}\right) L P M_{2}\left(R^{k}\right)-u\left(d_{1}\right) \geq 0 .
$$

$\Delta^{m}\left(d_{2}\right)$ equals the difference between the expected utility of waiting until $T=2, E[u(\cdot)]$, and the utility of withdrawing at $T=1, u\left(d_{1}\right)$. It depends on the expected shortfall, $L P M_{1}(\cdot)$, and the target semivariance, $\operatorname{LPM}_{2}(\cdot)$, which are disclosed by the bank. The return critical for bank solvency, $R^{k}$, is the relevant target. Usually $E[u(\cdot)]$ is lower than $u\left(d_{2}\right)$ because $d_{2}$ is only paid in solvency states. ${ }^{13}$ The higher $L P M_{1}(\cdot)$ and $L P M_{2}(\cdot)$, the lower is $E[u(\cdot)]$ and hence the difference $\Delta^{m}\left(d_{2}\right)$. Given the return $d_{2}$, the depositors decide to wait provided that asset risk is sufficiently low so that $\Delta^{m}\left(d_{2}\right)$ is nonnegative. ${ }^{14}$

Alternatively a depositor's withdrawal decision may be described as a function of the promised return, $d_{2}$, given the realised value of $\theta . \Delta^{m}\left(d_{2}\right)$ strictly increases in $d_{2}$ as long as the shortfall probablility, $\operatorname{LP}_{0}(\cdot)$, is lower than 1:

$$
\frac{\partial \Delta^{m}\left(d_{2}\right)}{\partial d_{2}}=u^{(1)}\left(d_{2}\right)\left(1-L P M_{0}\left(R^{k}\right)\right)>0 \quad \text { if } \quad L P M_{0}\left(R^{k}\right)<1 .
$$

\footnotetext{
12 Notice that $w<1$ and thus $R^{k}=d_{2} r / d_{1}$ because by calculating the expected utility of waiting until $T=2$, the depositor assumes that he himself does not withdraw at $T=1$.

13 Only if assets are riskless $\left(\operatorname{LPM}_{1}(\cdot)=L P M_{2}(\cdot)=0\right)$, it holds that $E[u(\cdot)]=u\left(d_{2}\right)$.

14 By assumption the depositors wait until $T=2$ according to their preferences for consumption if they are indifferent between withdrawal at $T=1$ and waiting until $T=2$.
} 
Even though the critical return for bank solvency, $R^{k}=d_{2} r / d_{1}$, and thus $L P M_{1}(\cdot)$ and $L P M_{2}(\cdot)$ increase in $d_{2}$, a high $d_{2}$ is optimal for the depositors. For a given $\theta$ it holds that the higher $d_{2}$ and thus $R^{k}$, the higher is the depositors' part of asset returns and the lower is the shareholders' part. As $\partial^{2} \Delta^{m}\left(d_{2}\right) / \partial d_{2}{ }^{2}<0, \Delta^{m}\left(d_{2}\right)$ reaches its maximum value if $d_{2}$ is so high that the bank is insolvent at $T=2$ with probability one, i.e. $\operatorname{LPM}_{0}(\cdot)=1$. Then a further increase in $d_{2}$ has no effect on the depositors' behaviour. They will get all asset returns at $T=2$ regardless of the realised value of $R$ because the bank will go bankrupt in any case. There is nothing left for the shareholders.

Depending on the return $d_{2}$ offered by the bank, the depositors' behaviour at $T=1$ can be written as follows:

$$
\begin{aligned}
& d_{2} \geq d_{2}^{m} \quad \Rightarrow \quad w=t \\
& d_{2}<d_{2}^{m} \quad \Rightarrow \quad w=1
\end{aligned}
$$

where $d_{2}^{m}$ is implicitly defined by $\Delta^{m}\left(d_{2}^{m}\right)=0$. Only if the risk premium is high enough (compared to the risk disclosed), depositors are willing to keep their deposits in the bank $(w=t)$. Otherwise we will observe a total bank run $(w=1)$.

In period $T=1$ the bank maximises expected net worth at $T=2$. The final net worth equals the difference between asset returns and promised returns on deposits not yet withdrawn (see also eq. (3)) provided that the bank is liquid at $T=1$ and solvent at $T=2$. Taking into account the depositors' reactions described above we can calculate the expected final net worth as (see appendix A.2, p. 22)

$$
\begin{aligned}
& E\left[V\left(d_{2}, w\right)\right]=E\left[\max \left\{0, R(1-w) \frac{d_{1}}{r} D-(1-w) d_{2} D\right\}\right] \\
& = \begin{cases}(1-t) \frac{d_{1}}{r} D\left(E[R]-R^{k}+L P M_{1}\left(R^{k}\right)\right) & \text { if } \quad \begin{array}{l}
w=t, \\
0
\end{array} \quad w=1 .\end{cases}
\end{aligned}
$$

If only the depositors of type 1 withdraw their deposits $(w=t), E\left[V\left(d_{2}, w\right)\right]$ may be positive. The expected shortfall, $L P M_{1}\left(R^{k}\right)$, is the relevant risk measure. The higher $\theta$, holding $R^{k}$ constant, the higher is $\operatorname{LPM}_{1}\left(R^{k}\right)$ - at least for some $R^{k} \in[0, \bar{R}]-$, and the higher is the expected final net worth because, due to its limited liability, the bank has to pay less to depositors at $T=2$. If all depositors withdraw at $T=1(w=1)$, the bank will be liquidated. The final net worth is zero.

The bank, which reports on the true values of $L P M_{1}(\cdot)$ and $L P M_{2}(\cdot)$, anticipates whether the depositors prefer to withdraw or to wait. The bank can prevent a bank run by offering a return $d_{2}$ which fulfills the inequality in (7). This might be optimal although, for $w=t$ 
and $\operatorname{LPM}_{0}(\cdot)<1$, the expected final net worth decreases in $d_{2}$ :

$$
\frac{\partial E\left[V\left(d_{2}, t\right)\right]}{\partial d_{2}}=(1-t) D\left(1-L P M_{0}\left(R^{k}\right)\right)<0 .
$$

Result $1 A$ bank that reports on its risk exposure offers a return on deposits, $d_{2}^{m}$, if $L P M_{0}\left(d_{2}^{m} r / d_{1}\right)<1 . \quad d_{2}^{m}$ is implicitly defined by $\Delta^{m}\left(d_{2}^{m}\right)=0$. The depositors accept this offer and leave their deposits at the bank.

If $\operatorname{LPM}_{0}\left(d_{2}^{m} r / d_{1}\right)=1$, the bank will not offer an adjustment of the return on deposits. The depositors' reaction to the bank's risk reporting is as follows: $w\left(d_{2}^{v} \geq d_{2}^{m}\right)=t$ and $w\left(d_{2}^{v}<d_{2}^{m}\right)=1$, respectively.

Proof: See appendix A.3, p. 22.

The bank will pay the return $d_{2}^{m}$, which prevents a bank run $(w=t)$, if its expected final net worth, $E\left[V\left(d_{2}^{m}, t\right)\right]$, is higher than in case of a total bank run $(w=1)$ and thus higher than zero. The expected final net worth is equal to zero if and only if the shortfall probability, $\operatorname{LPM}_{0}\left(d_{2}^{m} r / d_{1}\right)$, equals one. That means the return on deposits required by depositors to keep their deposits at the bank is so high that irrespective of $R$ the bank goes bankrupt at $T=2$.

If the bank does not offer $d_{2}^{m}$ due to $L P M_{0}\left(d_{2}^{m} r / d_{1}\right)=1$, the bank will either be liquidated at $T=1$ or insolvent at $T=2$. A return on deposits initially agreed upon and still valid at $T=1$ that is lower than $d_{2}^{m}$ leads to a risk-based bank run at $T=1 .{ }^{15}$ This bank run is caused by the information about asset risk related to the risk premium offered by the bank. From the depositors' point of view, the risk is too high for the contracted return on deposits. If at $T=0$ the bank and its depositors have agreed upon a return, $d_{2}^{v}$, that is higher than $d_{2}^{m}$, the bank becomes insolvent at $T=2$ irrespective of the realised value of $R$. The depositors decide to wait until $T=2$ as the expected utility of the liquidation value of bank assets (per deposit) is as high as the utility of withdrawal. Bank solvency at $T=2$ would only be possible if the return on deposits fell below $d_{2}^{m}$. However, depositors would not accept such an offer but withdraw their deposits at $T=1$. Therefore, the bank refrains from changing the return on deposits.

\section{Equilibrium Behaviour Without Risk Reporting}

In this section the benchmark scenario without risk reporting is analysed. In period $T=1$ the bank receives the same information as in the previous scenario. Again it has to decide

\footnotetext{
15 We call it risk-based instead of information-based bank run to emphasise that a certain kind of information, namely information about asset risk, is disclosed.
} 
whether to adjust the return on deposits anticipating the depositors' reactions to such an adjustment. The depositors are not informed on asset risk but have certain prior beliefs.

Given the return on deposits, $d_{2}$, and based on the a priori probabilities, $p(\theta)$, a depositor decides not to withdraw his deposit at $T=1$ if the difference between the expected utility of the return at $T=2$ and the utility of $d_{1}$ is nonnegative:

$$
\begin{aligned}
\Delta^{o}\left(d_{2}, p(\theta)\right) & =\sum_{\theta \in \Theta} p(\theta) \Delta^{m}\left(d_{2} \mid \theta\right) \\
& =u\left(d_{2}\right)-\frac{d_{1}}{r} u^{(1)}\left(d_{2}\right) L \widehat{P} M_{1}\left(R^{k}\right)+\frac{d_{1}{ }^{2}}{2 r^{2}} u^{(2)}\left(d_{2}\right) L \widehat{P} M_{2}\left(R^{k}\right)-u\left(d_{1}\right) \\
& \geq 0
\end{aligned}
$$

where $L \widehat{P} M_{i}\left(R^{k}\right)=\sum_{\theta \in \Theta} p(\theta) L P M_{i}\left(R^{k} \mid \theta\right), \quad i=0,1,2$.

If we compare condition (11) with condition (5), it becomes clear that the depositors' decisions are no longer based on (the true values of) $L P M_{1}(\cdot)$ and $L P M_{2}(\cdot)$ but on their beliefs concerning asset risk, $L \widehat{P} M_{1}(\cdot)$ and $L \widehat{P} M_{2}(\cdot)$.

Like in the scenario with risk reporting, waiting until $T=2$ becomes more advantageous (or less disadvantageous) when $d_{2}$ increases,

$$
\frac{\partial \Delta^{o}\left(d_{2}, p(\theta)\right)}{\partial d_{2}}=u^{(1)}\left(d_{2}\right)\left(1-L \widehat{P} M_{0}\left(R^{k}\right)\right)>0, \quad \text { as long as } \quad L \widehat{P} M_{0}\left(R^{k}\right)<1 .
$$

The depositors decide to withdraw if the return $d_{2}$ is so low that $\Delta^{o}\left(d_{2}, p(\theta)\right)$ is negative. Thus it holds for $\Delta^{o}\left(d_{2}^{o}, p(\theta)\right)=0$ :

$$
\begin{aligned}
& d_{2} \geq d_{2}^{o} \quad \Rightarrow \quad w=t \\
& d_{2}<d_{2}^{o} \Rightarrow w=1
\end{aligned}
$$

The depositors' behaviour depends on their beliefs, which, however, could change because of the decision of the bank. The depositors update their beliefs if the return on deposits offered by the bank at $T=1$ provides some information on asset risk. Then $d_{2}$ serves as a signal for $L P M_{1}(\cdot)$ and $L P M_{2}(\cdot)$, and in $(11) p(\theta)$ is substituted by $p\left(\theta \mid d_{2}\right)$.

The bank maximises its expected final net worth. Taking into account (13) and (14) we get (see again appendix A.2, p. 22)

$$
E\left[V\left(d_{2}, w\right)\right]= \begin{cases}(1-t) \frac{d_{1}}{r} D\left(E[R]-R^{k}+L P M_{1}\left(R^{k}\right)\right) & \text { if } \quad \begin{array}{l}
w \\
0
\end{array} \\
w=1\end{cases}
$$

At first glance (15) looks like (9), but the returns $d_{2}^{m}$ and $d_{2}^{o}$, which define the borderline between bank run and waiting until $T=2$, are not necessarily identical. (They are in fact identical if $L P M_{1}(\cdot)=L \widehat{P} M_{1}(\cdot)$ and $L P M_{2}(\cdot)=L \widehat{P} M_{2}(\cdot)$.) 
As (10) still holds, the expected final net worth decreases in $d_{2}\left(\right.$ for $w=t$ and $L P M_{0}(\cdot)<$ 1). Therefore, the bank will not offer more than $d_{2}^{o}$. Since the negative relationship between $d_{2}$ and $E\left[V\left(d_{2}, t\right)\right]$ holds for each type of bank irrespective of its asset risk, a separating equilibrium where risky types of banks offer high returns on deposits and less risky types offer low returns does not exist. In case of high asset risk, a bank can imitate a bank with low asset risk and offer $d_{2}^{o}$ as well.

The bank will offer $d_{2}^{o}$ only if $E\left[V\left(d_{2}^{o}, t\right)\right]$ exceeds the expected final net worth in case of a bank run:

$$
E\left[V\left(d_{2}^{o}, t\right)\right]>E\left[V\left(d_{2}, 1\right)\right]=0 \quad \Leftrightarrow \quad E[R]>\frac{d_{2}^{o} r}{d_{1}}-L P M_{1}\left(\frac{d_{2}^{o} r}{d_{1}}\right) .
$$

Whether the inequalities in (16) are fulfilled for any type of bank, i.e. for any $\theta \in \Theta$ and hence for any $\operatorname{LPM}_{1}(\cdot)$, is decisive for the equilibrium in the game between bank and depositors. ${ }^{16}$ In the following we will show that different kinds of equilibria are possible.

Result 2 In the scenario without risk reporting, pooling equilibria exist in the game between bank and depositors, i. e. each type of bank offers $d_{2}^{o}$, if

$$
\operatorname{LPM}_{0}\left(\frac{d_{2}^{o} r}{d_{1}}\right)<1 \quad \forall \theta \in \Theta
$$

where $d_{2}^{o}$ is implicitly defined by $\Delta^{o}\left(d_{2}^{o}, p(\theta)\right)=0$.

The depositors behave as follows: $w\left(d_{2} \geq d_{2}^{o}\right)=t$ and $w\left(d_{2}<d_{2}^{o}\right)=1$. The possible equilibria only differ in the depositors' out-of-equilibrium beliefs, $p\left(\theta \mid d_{2} \neq d_{2}^{o}\right)$.

Proof: See appendix A.4, p. 23.

In a pooling equilibrium the inequalities in (16) are fulfilled for all $L P M_{1}(\cdot)$ and thus for all $\theta \in \Theta$. Regardless of its asset risk, the bank always sends the same signal offering $d_{2}^{o}$. Therefore, the depositors are not able to update their prior beliefs.

Figure 2, p. 32, shows an example with three possible values for $\theta$, i. e. three types of banks. The risk increases in $\theta$ insofar as $L P M_{1}\left(R^{k} \mid \theta_{1}\right)<L P M_{1}\left(R^{k} \mid \theta_{2}\right)<L P M_{1}\left(R^{k} \mid \theta_{3}\right)$ with $\theta_{1}<\theta_{2}<\theta_{3}$ and $0<R^{k}=d_{2}^{o} r / d_{1}<\bar{R} .{ }^{17}$ Moreover, it holds that $L P M_{0}\left(R^{k}\right)<1$ for all $R^{k}<\bar{R}$ and for all $\theta$. The expected return, $E[R]$, is publicly known and therefore constant.

\footnotetext{
16 Notice that $E[R]$ is publicly known and hence the same for all types of banks. Therefore, an increase in $\theta$ leads to a mean preserving spread.

$17 L P M_{1}\left(R^{k}\right)$ may be geometrically interpreted as the area under the curve of $F(R)$ between 0 and $R^{k}$. Notice that the shortfall probability decreases in $\theta$ for all $R^{k} \in(E[R], \bar{R}): L P M_{0}\left(R^{k} \mid \theta_{1}\right)>$ $L P M_{0}\left(R^{k} \mid \theta_{2}\right)>L P M_{0}\left(R^{k} \mid \theta_{3}\right)$.
} 
As long as $d_{2}^{o}$ is lower than its maximum value, $\bar{R} d_{1} / r$, which means that $R^{k}=d_{2}^{o} r / d_{1}<\bar{R}$, a pooling equilibrium exists. Table 1, p. 32, provides another, numerical example of a pooling equilibrium. Each type of bank offers $d_{2}^{o}=1.2629$ to prevent a bank run as the expected final net worth, $E\left[V\left(d_{2}^{o}, t\right)\right]$, is always positive.

Result 3 Adverse selection is observed in the game between bank and depositors if

$$
\operatorname{LPM}_{0}\left(\frac{d_{2}^{o} r}{d_{1}}\right)=1 \quad \text { for at least one but not all } \theta \in \Theta
$$

and if $d_{2}^{o} \neq d_{2}^{v} \neq d_{2}^{o *}$. $d_{2}^{o}$ is implicitly defined by $\Delta^{o}\left(d_{2}^{o}, p(\theta)\right)=0$ whereas $d_{2}^{o *}$ is given by $\Delta^{o}\left(d_{2}^{o *}, p\left(\theta \mid d_{2}^{o *}\right)\right)=0$.

We may observe partial pooling as well as lemon equilibria where only the riskiest type of banks offers an adjusted return on deposits, $d_{2}^{o *}$. If, however, $L P M_{0}\left(d_{2}^{m} r / d_{1} \mid \bar{\theta}\right)=1$, even the riskiest type refrains from offering a new return on deposits.

Proof: See appendix A.5, p. 24.

The examples in Tables 1,2 , and 3 differ in the a priori probabilities, $p(\theta)$. Due to the increase in $p\left(\theta_{3}\right)$ and the simultaneous reduction in $p\left(\theta_{1}\right)$ and $p\left(\theta_{2}\right), L \widehat{P} M_{1}(\cdot)$ and $L \widehat{P} M_{2}(\cdot)$ increase. Therefore, the depositors require a priori a higher risk premium so that $d_{2}^{o}$ increases as well: $1.2629<1.6128<1.8434$.

In the example in Table 3 the a priori required return on deposits, $d_{2}^{o}=1.8434$, is too high for the bank with the lowest asset risk, i. e. the lowest $L P M_{1}(\cdot)$ (and $L P M_{2}(\cdot)$ ). It would become insolvent at $T=2$ irrespective of the realisation of $R$ if it offered $d_{2}^{o}$. As the expected final net worth would be zero, the bank refrains from offering $d_{2}^{o}$ but sticks to $d_{2}^{v}$. Only the riskier banks would like to offer $d_{2}^{o}=1.8434$. Knowing this, the depositors update their beliefs. Finally, adverse selection leads to a lemon equilibrium. The depositors expect the highest risk, and only the riskiest type of bank offers a return on deposits, $d_{2}^{o *}=1.9770$, that prevents a bank run and makes sure that the expected final net worth is positive $\left(E\left[V\left(d_{2}^{o *}, t\right)\right]=3.1322\right)$. If, however, $\theta_{1}$ or $\theta_{2}$ are realised, the depositors withdraw their deposits because the initially promised return, which is still valid, is lower than the equilibrium return, $d_{2}^{v}<d_{2}^{o *}$.

If $d_{2}^{v}>d_{2}^{o *}$ and asset risk is rather low so that $E\left[V\left(d_{2}^{o *}, t\right)\right]=0$, the depositors' behaviour is somewhat different. The return on deposits agreed upon at $T=0$ induces bankruptcy at $T=2$ irrespective of the realised value of asset returns whereas the reduction necessary for the possibility of bank solvency at $T=2$ would lead to a bank run and thus liquidation 
at $T=1$. As the bank cannot improve $E[V(\cdot)]$, it does not offer $d_{2}^{o *}$ but stick to the "old" return on deposits, $d_{2}^{v}$. Because of $d_{2}^{v}>d_{2}^{o *}$ the depositors decide not to withdraw at $T=1$ but wait for the liquidation value of the insolvent bank at $T=2$. A bank run that induces the banks with lower asset risk to leave the market at $T=1$ cannot be observed. Instead these types of banks will go bankrupt at $T=2$, thus leaving the market at $T=2$.

If the critical return on deposits that is based on the depositors' prior beliefs equals the initially contracted return, $d_{2}^{o}=d_{2}^{v}$, another pooling equilibrium can be observed. In this case the lowest value of $d_{2}$ that prevents a bank run at $T=1$ has already been contracted at $T=0$. Therefore, the bank has no incentive to change it and does not offer a new return on deposits. It always sends the same signal regardless of its asset risk. In the example of Table 2, p. 33, and Table 3, p. 34, such pooling equilibria would exist if $d_{2}^{v}=1.6128$ and 1.8434 , respectively.

Result 4 In the scenario without risk reporting, pooling equilibria without a change in the return on deposits exist in the game between bank and depositors if

$$
d_{2}^{v}=d_{2}^{o}
$$

$d_{2}^{o}$ is implicitly defined by $\Delta^{o}\left(d_{2}^{o}, p(\theta)\right)=0$.

A bank run cannot be observed. The possible equilibria only differ in the depositors' out-ofequilibrium beliefs, $p\left(\theta \mid d_{2} \neq d_{2}^{o}\right)$.

Proof: See appendix A.6, p. 25.

An overview of the various equilibria in the game between bank and depositors without risk reporting is provided in Table 4, p. 34. The pooling equilibria described in Result 2 can be found in the central column whereas the pooling equilibria of Result 4 are characterised by $d_{2}^{o}=d_{2}^{v}$ (see third row). According to Result 3 partial pooling or lemon equilibrium can be observed if the bank's expected final net worth is not always positive (see third column) and if the return on deposits contracted at $T=0, d_{2}^{v}$, is neither equal to the critical return based on the depositors' prior beliefs, $d_{2}^{o}$, nor to the equilibrium return, $d_{2}^{o *}$.

\section{$5 \quad$ Effects of Risk Reporting}

In equilibrium a bank reporting on its asset risk offers a return on deposits, $d_{2}^{m}$, which is just high enough to prevent a (risk-based) bank run, provided that the expected final net worth 
is still positive. If the bank does not inform about asset risk, different kinds of equilibria are possible. A pooling equilibrium may be observed, i. e. at $T=1$ each type of bank offers the same return on deposits, $d_{2}^{o}$. The depositors keep their deposits in the bank. Besides, we have found equilibria where only the riskiest types of banks offer an adequate return on deposits whereas less risky types leave the market. In the following, let us assume that the bank has not disclosed its asset risk so far and now risk reporting is introduced. What are the effects of risk reporting?

Result 5 Provided that without risk reporting each type of bank offers the same return on deposits and no bank run occurs (pooling equilibrium), risk reporting leads to a higher risk exposure of rather risky types of banks (or to a bank run on these banks) while reducing the risk exposure of banks with already quite low asset risk.

Proof: See appendix A.7, p. 25.

On the one hand, a bank with higher asset risk than a priori expected has to pay a higher return on deposits in case of risk reporting than without risk reporting $\left(d_{2}^{m}>d_{2}^{o}\right)$. The increase in the equilibrium return on deposits, however, raises the bank's liabilities at $T=2$ and hence the return on assets critical for bank solvency, $R^{k}$. Finally insolvency risk increases, i. e. $L P M_{1}\left(R^{k}\right)$ and $L P M_{2}\left(R^{k}\right)$ rise, as long as $L P M_{0}\left(R^{k}\right)>0$. If such a bank refused to pay $d_{2}^{m}$ but still offered $d_{2}^{o}$, a bank run would occur because the risk premium would be too low.

On the other hand, a quite riskless bank may reduce the return on deposits without increasing the danger of a bank run if it reports on its asset risk. As a consequence insolvency risk of this already rather riskless bank is lower in case of risk reporting than without risk reporting. However, this reduction in insolvency risk cannot be observed if without risk reporting the bank is already riskless, which means that the promised return, $d_{2}^{o}$, is so low that $L P M_{0}\left(R^{k}\right)=L P M_{1}\left(R^{k}\right)=L P M_{2}\left(R^{k}\right)=0$. Then depositors will get $d_{2}^{o}$ at $T=2$ irrespective of the realised value of asset returns.

If we suppose a lemon equilibrium or partial pooling as described in Result 3, risk reporting helps to overcome the problem of adverse selection. Not only very risky types of banks, but also banks with lower asset risk are able to continue their business until $T=2$ because they can credibly communicate their low risk. Therefore, a rather riskless bank can pay a lower return on deposits than in equilibrium without risk reporting. As the depositors know the true asset risk, they are willing to keep their deposits in the bank if it promises to pay $d_{2}^{m}$ at $T=2$. Provided that its expected final net worth is positive, which means 
that the bank will not automatically go bankrupt at $T=2\left(L P M_{0}\left(d_{2}^{m} r / d_{1}\right)<1\right)$, the bank indeed offers $d_{2}^{m}$. Then bank runs do not take place at $T=1$.

Result 6 If without risk reporting only the riskiest types of banks offer a return on deposits which is accepted by the depositors, risk reporting may help to prevent this adverse selection. Provided that $L_{P} M_{0}\left(d_{2}^{m} r / d_{1}\right)<1$ also less risky types of banks offer a return, $d_{2}^{m}$, that prevents a bank run and does not automatically lead to bank insolvency at $T=2$.

Proof: For less risky types of banks it holds that $L P M_{1}\left(d_{2}^{m} r / d_{1}\right)<L P M_{1}\left(d_{2}^{o *} r / d_{1}\right)<$ $L \widehat{P} M_{1}\left(d_{2}^{o *} r / d_{1} \mid d_{2}^{o *}\right)$ and $L P M_{2}\left(d_{2}^{m} r / d_{1}\right)<L P M_{2}\left(d_{2}^{o *} r / d_{1}\right)<L \widehat{P} M_{2}\left(d_{2}^{o *} r / d_{1} \mid d_{2}^{o *}\right)$ where $d_{2}^{m}<$ $d_{2}^{o} \cdot{ }^{18}$ If $d_{2}^{m}$ is sufficiently low, ${ }_{L P} M_{0}\left(d_{2}^{m} r / d_{1}\right)<L P M_{0}\left(d_{2}^{o *} r / d_{1}\right)=1$ so that the bank promises $d_{2}^{m}$ in case of risk reporting whereas it does not offer a change in $d_{2}$ without risk reporting.

To sum up, risk reporting may reduce the banks' risk exposure (or reduce the possibility of bank runs), but also raise the risk exposure of certain types of banks (or increase the possibility of bank runs on these types). Which of these effects actually occurs depends on the benchmark scenario and hence on the parameters of the model. An increase in risk can only be observed if without risk reporting there exists a pooling equilibrium and the bank is rather risky. The impact of the return on deposits agreed upon at $T=0$ can be seen in Result 4. If $d_{2}^{v}=d_{2}^{o}$, there exists a pooling equilibrium in the game between bank and depositors. But even if $d_{2}^{v} \neq d_{2}^{o}$ such an equilibrium may be observed depending on the other parameters.

Result 7 Risk reporting may lead to an increase in risk of already rather risky types of banks. This effect is the more likely,

a) the less risk averse the depositors,

b) the lower the return on assets at $T=1$ (per invested dollar),

c) the higher the a priori probability of quite low asset risk,

d) the smaller the difference between the highest and the lowest level of asset risk.

18 See proof of Result 5, p. 25. Since the depositors' posterior beliefs do no longer equal their prior beliefs we explicitly refer to the posterior beliefs. $L \widehat{P} M_{i}\left(d_{2}^{o *} r / d_{1} \mid d_{2}^{o *}\right), i=1,2$, symbolises the expected Lower Partial Moment $i$ based on the a posteriori probabilities, $p\left(\theta \mid d_{2}^{o *}\right)$. 
Proof: See appendix A.8, p. 26.

The parameters mentioned in a), b), and c) influence the return on deposits, $d_{2}^{o}$, which is necessary to prevent a bank run in case of no risk disclosure. The lower this return, the more likely it is that less risky types of banks may also be able to offer $d_{2}^{o}$ thus gaining a positive expected net worth at $T=2$. Therefore, a pooling equilibrium becomes more likely.

Depositors who are not so much risk averse require a rather low risk premium. As a consequence, the critical return on deposits, $d_{2}^{o}$, is quite low. As an example, take the data from Tables 2 and 3 and substitute the utility function by $u\left(d_{i}\right)=-2 d_{i}{ }^{2}+23.76 d_{i}, i=1,2$, which shows lower absolute risk aversion. Then pooling equilibria exist in both examples with $d_{2}^{o}=1.4691$ and $d_{2}^{o}=1.5797$, respectively.

According to (2) a quite low return on assets in period $T=1, r$, implies c. p. a rather low level of the debt-to-equity ratio. Therefore, the return on assets critical for bank solvency, $R^{k}$, is rather low as well. The lower $r$, the lower is $R^{k}$, the higher is the depositors' expected utility of waiting until $T=2$, and finally the lower is the critical return on deposits that prevents a bank run. ${ }^{19}$

If a priori the probability of low asset risk is high and accordingly the probability of high asset risk is low, the depositors expect ex ante rather low asset risk. Therefore, the return on deposits that is critical for waiting until $T=2$ is not that high. The examples in Tables 1,2 , and 3 , which differ in $p(\theta)$, thus leading to different equilibria, support this statement.

The argument behind d) is somewhat different: The true asset risk of a bank, $L P M_{1}(\cdot)$ and $L P M_{2}(\cdot)$, usually deviates from the depositors' prior beliefs, $L \widehat{P} M_{1}(\cdot)$ and $L \widehat{P} M_{2}(\cdot)$. Therefore, $d_{2}^{o}$, which is based on the prior beliefs, is different from $d_{2}^{m}$, which is calculated knowing asset risk. The smaller the difference between highest and lowest possible values of $L P M_{1}(\cdot)$ and $L_{P} M_{2}(\cdot)$, the smaller is c. p. the possible deviation of low asset risk from prior beliefs. As a consequence, $d_{2}^{o}$ does not differ very much from $d_{2}^{m}$ so that a pooling equilibrium in the scenario without risk reporting is more plausible.

So far we have analysed how insolvency risk of certain types of banks in case of risk reporting differs from insolvency risk if these banks do not report on their risk. We have shown that ex post a bank's risk exposure may be higher with risk reporting than without risk reporting. Additionally we can identify conditions under which the ex ante risk exposure

19 Notice that the impact of a change of $d_{1}$ on the kind of equilibrium in the scenario without risk reporting is not clear. It can easily be shown that a rise in $d_{1}$ increases the expected utility of waiting until $T=2$. But at the same time it increases the utility of withdrawing the deposits at $T=1$ so that it is not clear whether the bank has to raise the return on deposits at $T=2, d_{2}$, to prevent a bank run. 
may increase. As a necessary condition, a pooling equilibrium must exist when the bank does not report on its risk.

Result 8 Provided that without risk reporting a bank offers the same return on deposits irrespective of its asset risk (pooling equilibrium), the risk exposure can a priori be higher with risk reporting than without risk reporting. This ex ante increase in risk is the more likely,

a) the higher the a priori probability of rather high asset risk,

b) the higher (smaller) the difference between the risk exposure with risk reporting and the risk exposure without risk reporting if the bank is rather risky (riskless) without risk reporting.

Proof: See appendix A.9, p. 27.

A priori risk reporting leads to an increase in insolvency risk compared to the scenario without risk reporting if it is ex ante expected that the risk increasing effect on risky types of banks more than compensates the risk decreasing effect on quite riskless types of banks. Two factors are important for this result: firstly, the a priori probabilities of the possible types of banks, and secondly, the differences between asset risk with risk reporting and asset risk without risk reporting of the different types of banks. If the probability of rather risky types is high or the difference between asset risk with risk reporting and asset risk without risk reporting is high (small) if the bank is rather risky (riskless) without risk reporting, it is more likely that ex ante expected shortfall and target semivariance are higher with risk reporting. The impact of the second factor becomes clear if we only allow for two possible types of banks: a risky bank and a riskless bank. ${ }^{20}$ In case of risk reporting the risky bank becomes even more risky whereas the riskless bank still bears no risk. Regardless of the a priori probabilities of both types of banks, we observe an increase in the risk exposure due to risk reporting.

\section{Conclusion}

In this paper the impact of a bank's risk reporting on the equilibium behaviour of the bank and its depositors has been analysed. We have shown that risk reporting may not only

20 Cordella and Levy Yeyati (1998) refer to this special case when they state that the ex ante probability of bank insolvency increases. 
lead to a decrease but also to a rise in the bank's risk exposure. A final evaluation of risk reporting depends on which of the different equilibria in the benchmark scenario actually occurs. If the lack of risk disclosure leads to adverse selection because only in case of high asset risk a bank is active in the market for deposits, risk reporting may help to overcome this problem. However, in case of a pooling equilibrium which means that an "average" return on deposits is contracted irrespective of asset risk, risk reporting increases risk in situations with already high asset risk and decreases it in situations which are quite riskless. We have identified conditions under which a pooling equilibrium is more likely so that by the introduction of risk reporting "the bank is 'taxed' during hard times and 'rewarded' during good times" (Cordella and Levy Yeyati, 1998, p. 125). Moreover, ex ante expected shortfall and target semivariance may be higher in case of risk reporting.

Our conclusions confirm some of the results of Cordella and Levy Yeyati (1998) even though the analytical frameworks differ. We do not assume a uniform or other special distribution over asset returns, thus using risk measures that are independent of the underlying distribution function. Besides, more than two possible values of asset risk are considered. Instead of looking at the investment decisions of risk neutral potential debtholders, whom Cordella and Levy Yeyati (1998) call depositors, we have analysed the withdrawal decisions of risk averse depositors. Thus we gain additional insight into the impact of the depositors' prior beliefs and their risk aversion. Unlike Cordella and Levy Yeyati (1998) we have shown that even in case of risk reporting depositors and bank may not agree on a return on deposits so that risk-based bank runs are possible.

Referring to the theory of deposit contracts and bank runs we model not only the sequential game between bank and depositors, as Cordella and Levy Yeyati (1998) do, but also the simultaneous game between depositors. To our knowledge this is the first paper that analyses the effects of risk disclosure and takes into account the characteristics of deposit contracts. In this paper, we restrict ourselves to a scenario in which the game between depositors is characterised by dominant strategies. However, a simple change in the assumption on the level of equity would lead to a different game between depositors. For example, we may assume that equity is so low that the bank becomes illiquid provided that a certain fraction of deposits is withdrawn. Then a depositor's withdrawal decision does not only depend on his information (or expectation) about asset risk but also on his beliefs concerning the other depositors' behaviour. In addition to information-based bank runs, panic runs will occur. Nevertheless, the effects of risk reporting are quite similar to the ones described above. The opposite case, in which equity is so high that the bank does not go into liquidation even if all deposits are withdrawn, shows some different results. E.g., not only total, but also partial bank runs may be observed. A detailed description of this case 
goes far beyond the scope of this paper and will be presented somewhere else.

As another possible extension the bank might be allowed to influence risk by changing the distribution over asset returns. In our model, nature and not the bank chooses asset risk. So the analysis is concentrated on the part of a bank's risk that cannot be hedged by the bank, e.g. because it is influenced by macroeconomic factors. If the bank chooses asset risk, moral hazard instead of quality uncertainty is analysed in the scenario without risk reporting. However, this will not be discussed here any more but left for future research. 


\section{A Appendix}

\section{A.1 The Depositors' Expected Utility of the Return on Deposits at $T=2$}

Using integration by parts $n$ times, the expected utility of the return on deposits at $T=2$ can be transformed as follows:

$$
\begin{aligned}
& E\left[u\left(\min \left\{d_{2}, R \frac{d_{1}}{r}\right\}\right)\right] \\
& =\int_{0}^{R^{k}} u\left(R \frac{d_{1}}{r}\right) d F(R)+\int_{R^{k}}^{\bar{R}} u\left(d_{2}\right) d F(R) \\
& =\left[u\left(R \frac{d_{1}}{r}\right) F(R)\right]_{0}^{R^{k}}-\int_{0}^{R^{k}} F(R) u^{(1)}\left(R \frac{d_{1}}{r}\right) \frac{d_{1}}{r} d R+u\left(d_{2}\right)\left(1-F\left(R^{k}\right)\right) \quad \text { (step 1) } \\
& =u\left(d_{2}\right)-\frac{d_{1}}{r} \int_{0}^{R^{k}} u^{(1)}\left(R \frac{d_{1}}{r}\right) d F^{[1]}(R) \\
& =u\left(d_{2}\right)-\frac{d_{1}}{r} u^{(1)}\left(d_{2}\right) F^{[1]}\left(R^{k}\right)+\left(\frac{d_{1}}{r}\right)^{2} \int_{0}^{R^{k}} u^{(2)}\left(R \frac{d_{1}}{r}\right) d F^{[2]}(R) \\
& =u\left(d_{2}\right)-\frac{d_{1}}{r} u^{(1)}\left(d_{2}\right) F^{[1]}\left(R^{k}\right)+\left(\frac{d_{1}}{r}\right)^{2} u^{(2)}\left(d_{2}\right) F^{[2]}\left(R^{k}\right)-\left(\frac{d_{1}}{r}\right)^{3} \int_{0}^{R^{k}} u^{(3)}\left(R \frac{d_{1}}{r}\right) d F^{[3]}(R) \\
& \ldots \\
& =u\left(d_{2}\right)+\sum_{i=1}^{n-1}\left(-\frac{d_{1}}{r}\right)^{i} u^{(i)}\left(d_{2}\right) F^{[i]}\left(R^{k}\right)+\left(-\frac{d_{1}}{r}\right)^{n} \int_{0}^{R^{k}} u^{(n)}\left(R \frac{d_{1}}{r}\right) d F^{[n]}(R), \quad n>1 .
\end{aligned}
$$

For $\operatorname{LPM}_{i}\left(R^{k}\right)=i ! F^{[i]}\left(R^{k}\right)$ and $n>1$ it follows

$$
\begin{aligned}
E\left[u\left(\min \left\{d_{2}, R \frac{d_{1}}{r}\right\}\right)\right]= & u\left(d_{2}\right)+\sum_{i=1}^{n-1} \frac{1}{i !}\left(-\frac{d_{1}}{r}\right)^{i} u^{(i)}\left(d_{2}\right) L P M_{i}\left(R^{k}\right) \\
& +\left(-\frac{d_{1}}{r}\right)^{n} \int_{0}^{R^{k}} u^{(n)}\left(R \frac{d_{1}}{r}\right) d F^{[n]}(R)
\end{aligned}
$$

and finally for a utility function $u(\cdot)$ with $n-1$ derivatives it holds that

$$
E\left[u\left(\min \left\{d_{2}, R \frac{d_{1}}{r}\right\}\right)\right]=u\left(d_{2}\right)+\sum_{i=1}^{n-1} \frac{1}{i !}\left(-\frac{d_{1}}{r}\right)^{i} u^{(i)}\left(d_{2}\right) L P M_{i}\left(R^{k}\right)
$$




$$
\begin{aligned}
E\left[V\left(d_{2}, w\right)\right] & =E\left[\max \left\{0, R(1-w) \frac{d_{1}}{r} D-(1-w) d_{2} D\right\}\right] \\
& =\max \left\{0, \int_{R^{k}}^{\bar{R}}\left(R(1-w) \frac{d_{1}}{r} D-(1-w) d_{2} D\right) d F(R)\right\} \\
& =\max \left\{0,(1-w) \frac{d_{1}}{r} D \int_{R^{k}}^{\bar{R}}\left(R-R^{k}\right) d F(R)\right\} \\
& =\max \left\{0,(1-w) \frac{d_{1}}{r} D\left[R F(R)-F^{[1]}(R)-R^{k} F(R)\right]_{R^{k}}^{\bar{R}}\right\} \\
& =\max \left\{0,(1-w) \frac{d_{1}}{r} D\left[\bar{R}-F^{[1]}(\bar{R})-R^{k}+F^{[1]}\left(R^{k}\right)\right]\right\} \\
& =\left\{(1-w) \frac{d_{1}}{r} D\left(E[R]-R^{k}+L P M_{1}\left(R^{k}\right)\right) \quad \text { if } \quad \begin{array}{l}
w<1 \\
0
\end{array}\right.
\end{aligned}
$$

\section{A.3 Proof of Result 1}

If the bank offers a return $d_{2}$ with $\Delta^{m}\left(d_{2}\right) \geq 0,(5)$ is fulfilled so that $w=t$. Because of $(6)$ and (10) the bank does not offer more than $d_{2}^{m}$, which ist defined by $\Delta^{m}\left(d_{2}^{m}\right)=0$.

However, the bank offers $d_{2}^{m}$ only if $E\left[V\left(d_{2}^{m}, t\right)\right]>E\left[V\left(d_{2}, 1\right)\right]=0$. If the depositors were risk neutral, the last inequality would always be fulfilled. $\Delta^{m}\left(d_{2}^{m}\right)=0$ is then equivalent to

$$
d_{2}^{m}-\frac{d_{1}}{r} L P M_{1}\left(R^{k}\right)-d_{1}=0 \quad \Leftrightarrow \quad L P M_{1}\left(R^{k}\right)=R^{k}-r .
$$

so that inserting into (9) leads to

$$
\begin{aligned}
E\left[V\left(d_{2}^{m}, t\right)\right] & =(1-t) \frac{d_{1}}{r} D\left(E[R]-R^{k}+L P M_{1}\left(R^{k}\right)\right) \\
& =(1-t) \frac{d_{1}}{r} D(E[R]-r) \\
& >0 .
\end{aligned}
$$

In this paper, the depositors are by assumption risk averse. $\Delta^{m}\left(d_{2}^{m}\right)=0$ may be rewritten as

$$
L P M_{1}\left(R^{k}\right)=\frac{r}{d_{1}} \frac{u\left(d_{2}^{m}\right)-u\left(d_{1}\right)}{u^{(1)}\left(d_{2}^{m}\right)}+\frac{d_{1}}{2 r} \frac{u^{(2)}\left(d_{2}^{m}\right)}{u^{(1)}\left(d_{2}^{m}\right)} L P M_{2}\left(R^{k}\right)
$$

so that

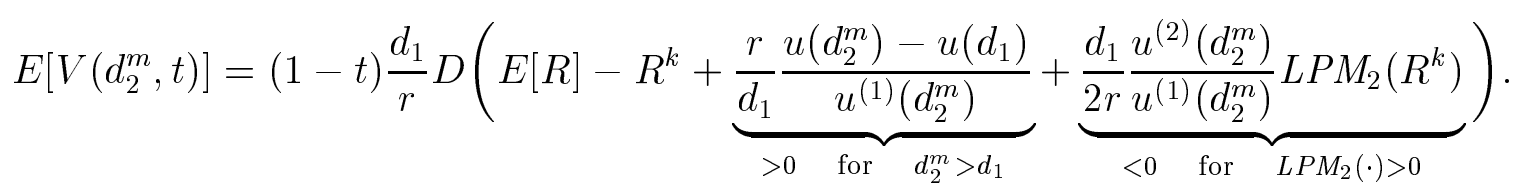


If the depositors are risk averse, the expected net worth at $T=2$ is not generally positive. The critical return, $d_{2}^{m}$, is higher than in case of risk neutral depositors due to the required risk premium. The higher the absolute risk aversion, i. e. the higher $-u^{(2)}\left(d_{2}^{m}\right) / u^{(1)}\left(d_{2}^{m}\right)$, the more likely it is that $E\left[V\left(d_{2}^{m}, t\right)\right]=0$.

$E\left[V\left(d_{2}^{m}, t\right)\right]=0$ is equivalent to $L P M_{0}\left(d_{2}^{m} r / d_{1}\right)=1$ : From

$$
\begin{aligned}
d_{2}^{m} & <\frac{\bar{R} d_{1}}{r} \\
E[R] & \equiv \int_{0}^{\bar{R}} R d F(R)=\bar{R} F(\bar{R})-F^{[1]}(\bar{R})=\bar{R}-\operatorname{LPM}_{1}(\bar{R}), \\
\operatorname{LPM}_{0}(\bar{R}) & =1, \quad \text { and } \quad 0 \leq \operatorname{LPM}_{0}\left(\frac{d_{2}^{m} r}{d_{1}}\right) \leq 1
\end{aligned}
$$

it follows that

$$
\begin{aligned}
E\left[V\left(d_{2}^{m}, t\right)\right]=0 & \Leftrightarrow \quad E[R]=\frac{d_{2}^{m} r}{d_{1}}-L P M_{1}\left(\frac{d_{2}^{m} r}{d_{1}}\right) \\
& \Leftrightarrow \quad 1=\frac{L P M_{1}(\bar{R})-L P M_{1}\left(\frac{d_{2}^{m} r}{d_{1}}\right)}{\bar{R}-\frac{d_{2}^{m} r}{d_{1}}} \\
& \Leftrightarrow \quad 1=L P M_{0}\left(\frac{d_{2}^{m} r}{d_{1}}\right),
\end{aligned}
$$

and

$$
E\left[V\left(d_{2}^{m}, t\right)\right]>0 \quad \Leftrightarrow \quad 1>L P M_{0}\left(\frac{d_{2}^{m} r}{d_{1}}\right) .
$$

Moreover, it holds:

$$
d_{2}^{m}=\frac{\bar{R} d_{1}}{r} \Rightarrow \operatorname{LPM}_{0}\left(\frac{d_{2}^{m} r}{d_{1}}\right)=L P M_{0}(\bar{R})=1 \quad \text { and } \quad E\left[V\left(d_{2}^{m}, t\right)\right]=0 .
$$

If $d_{2}=d_{2}^{v}$ is not changed due to $L P M_{0}\left(d_{2}^{m} r / d_{1}\right)=1,(7)$ und (8) describe the depositors' reactions.

\section{A.4 Proof of Result 2}

The first part of the proof is similar to the proof of Result 1: If the bank offers a return $d_{2}^{o}$ which fulfills $\Delta^{o}\left(d_{2}, p(\theta)\right) \geq 0$, it holds that $w=t$. Because of (10) and (12) the bank does not offer more than $d_{2}^{o}$, which is defined by $\Delta^{o}\left(d_{2}^{o}, p(\theta)\right)=0$. According to (16), $d_{2}^{o}$ will be offered only if $E\left[V\left(d_{2}^{o}, t\right)\right]>0$. This condition is equivalent to $L P M_{0}\left(d_{2}^{o} r / d_{1}\right)<1$ (see (18)). If $L P M_{0}\left(d_{2}^{o} r / d_{1}\right)<1 \forall \theta \in \Theta$, each type of bank offers $d_{2}^{o}$ so that $p\left(d_{2}^{o} \mid \theta\right)=1 \forall \theta \in \Theta$. 
With this the conditions of a perfect Bayesan equilibrium are fulfilled. ${ }^{21}$ It holds that

$$
E\left[V\left(d_{2}^{o}, w\right)\right]>E\left[V\left(d_{2}, w\right)\right] \quad \forall \theta \in \Theta, d_{2} \in \mathcal{D}, d_{2} \neq d_{2}^{o}
$$

where $w$ symbolises the depositors equilibrium behaviour (see Result 2), and

$$
\Delta^{o}\left(d_{2}^{o}, p\left(\theta \mid d_{2}^{o}\right)\right)=\Delta^{o}\left(d_{2}^{o}, p(\theta)\right)=0
$$

because from $p\left(d_{2}^{o} \mid \theta\right)=1 \forall \theta \in \Theta$ it follows

$$
p\left(\theta \mid d_{2}^{o}\right)=\frac{p(\theta) p\left(d_{2}^{o} \mid \theta\right)}{\sum_{j \in \Theta} p(j) p\left(d_{2}^{o} \mid j\right)}=p(\theta) .
$$

Finally, various out-of-equilibrium beliefs support the pooling equilibrium. In case of passive conjectures $^{22}$, prior beliefs are retained, $p\left(\theta \mid d_{2} \neq d_{2}^{o}\right)=p(\theta)$, so that it is never optimal for the bank to deviate from the equilibrium. The critical value for waiting until $T=2$ is still $d_{2}^{o}$

$$
p\left(\theta \mid d_{2} \neq d_{2}^{o}\right)= \begin{cases}1 & \text { if } \theta=\bar{\theta} \\ 0 & \text { else. }\end{cases}
$$

also supports the equilibrium return on deposits, $d_{2}^{o}$. The depositors believe that if a bank chooses an out-of-equilibrium return on deposits, it is always the most risky bank, i.e. $L P M_{1}(\cdot)$ is at maximum. Because of (10) such a bank may want to reduce $d_{2}$ to $d_{1}$. As the depositors would withdraw their deposits $(w=1)$ and $E\left[V\left(d_{1}, 1 \mid \bar{\theta}\right)\right]=0<E\left[V\left(d_{2}^{o}, t \mid \bar{\theta}\right)\right]$, it is not optimal for the bank to deviate from the pooling equilibrium with $d_{2}^{o}$.

\section{A.5 Proof of Result 3}

According to (16) a bank does not offer $d_{2}^{o}$ if $E\left[V\left(d_{2}^{o}, t\right)\right]=0$. This condition is equivalent to $L P M_{0}\left(d_{2}^{o} r / d_{1}\right)=1$ (see proof of Result 1 ). If $E\left[V\left(d_{2}^{o}, t\right)\right]=0$ holds for at least one (but not for all) $\theta \in \Theta$, the banks with the lowest values of $L P M_{1}(\cdot)$ will not offer $d_{2}^{o}$ because $E\left[V\left(d_{2}^{o}, t\right)\right]$ increases in $L P M_{1}(\cdot)$. Since the inequalities in (16) do not hold, such type of bank leaves $d_{2}^{v} \neq d_{2}^{o}$ unchanged. ${ }^{23}$ Only rather risky banks offer $d_{2}^{o}$.

The possibility of partial pooling and lemon equilibria are proved with the help of two numerical examples. Table 2, p. 33, shows partial pooling (or partial adverse selection) with

\footnotetext{
21 See Fudenberg and Tirole (1991), pp. 325 f.

22 See Rasmusen (2001), p. 142.

23 If $d_{2}^{v}=d_{2}^{o}$, we have another pooling equilibrium. See Result 4, p. 14 .
} 
an equilibrium return of $d_{2}^{o *}=1.6590$, which is contracted only in case of middle or high risk. The depositors update their beliefs accordingly. A lemon equilibrium is presented in Table 3 , p. 34. Only the riskiest bank offers the critical return on deposits, $d_{2}^{o *}=1.9770$, which is based on the depositors' posterior beliefs, $p\left(\theta_{1} \mid d_{2}^{o *}\right)=p\left(\theta_{2} \mid d_{2}^{o *}\right)=0$ and $p\left(\theta_{3} \mid d_{2}^{o *}\right)=1$.

From $p\left(\bar{\theta} \mid d_{2}^{o *}\right)=1$ it follows ${ }^{24}$

$$
L \widehat{P} M_{i}\left(d_{2}^{o *} r / d_{1} \mid d_{2}^{o *}\right) \equiv \sum_{\theta \in \Theta} p\left(\theta \mid d_{2}^{o *}\right) L P M_{i}\left(d_{2}^{o *} r / d_{1} \mid \theta\right)=L P M_{i}\left(d_{2}^{o *} r / d_{1} \mid \bar{\theta}\right), \quad i=0,1,2
$$

so that $0=\Delta^{o}\left(d_{2}^{o *}, p\left(\theta \mid d_{2}^{o *}\right)\right)=\Delta^{m}\left(d_{2}^{o *} \mid \bar{\theta}\right)$ and finally $d_{2}^{o *}=d_{2}^{m}$. If, however, $L P M_{0}\left(d_{2}^{m} r / d_{1} \mid \bar{\theta}\right)$ $=1, d_{2}^{m}$ is not even paid by the riskiest bank (see Result 1 ).

If $d_{2}^{o *}=d_{2}^{v}$, no type of bank would change the return on deposits. Therefore, $p\left(d_{2}^{o *} \mid \theta\right)=$ $1 \forall \theta \in \Theta$ and finally $p\left(\theta \mid d_{2}^{o *}\right)=p(\theta)$ (see proof of Result 2). From $\Delta^{o}\left(d_{2}^{o}, p(\theta)\right)=0$, $d_{2}^{o *}>d_{2}^{o}$, and (12) it follows that $\Delta^{o}\left(d_{2}^{o *}, p(\theta)\right)>0$. According to (13) and (14) it holds that $w\left(d_{2} \geq d_{2}^{o}\right)=t$ and $w\left(d_{2}<d_{2}^{o}\right)=1$ and thus - for $L P M_{0}\left(d_{2}^{o *} r / d_{1}\right)<1$ (see $\left.(10)\right)-$ $E\left[V\left(d_{2}^{o *}, w\right)\right]<E\left[V\left(d_{2}, w\right)\right]$ where $d_{2} \in\left[d_{2}^{o}, d_{2}^{o *}\right]$. Therefore, a (perfect Bayesian) equilibrium with $d_{2}^{o *}=d_{2}^{v}$ does not exist.

\section{A.6 Proof of Result 4}

If $\Delta^{o}\left(d_{2}^{v}, p(\theta)\right)=0,(13)$ is fulfilled for $d_{2}^{v}=d_{2}^{o}$ so that $w=t$. If $L P M_{1}\left(d_{2}^{v} r / d_{1}\right)$ is so low that $E\left[V\left(d_{2}^{v}, t\right)\right]=0, E\left[V\left(d_{2}^{v}, t\right)\right]=E\left[V\left(d_{2}<d_{2}^{v}, 1\right)\right]=E\left[V\left(d_{2}>d_{2}^{v}, t\right)\right]$ according to (10), (13), (14), and (15). If $L P M_{1}\left(d_{2}^{v} r / d_{1}\right)$ is rather high so that $E\left[V\left(d_{2}^{v}, t\right)\right]>0, E\left[V\left(d_{2}^{v}, t\right)\right]>$ $E\left[V\left(d_{2}>d_{2}^{v}, w\right)\right]$ according to (10) and (13). Moreover, it holds that $E\left[V\left(d_{2}^{v}, t\right)\right]>E\left[V\left(d_{2}<\right.\right.$ $\left.\left.d_{2}^{v}, w\right)\right]$ because of (14) and (15). Irrespective of $\theta$ and thus of $L P M_{1}\left(d_{2}^{v} r / d_{1}\right)$, the condition for offering a new return on deposits, $d_{2}^{o} \neq d_{2}^{v}$, in (16) is not fulfilled.

Each type of banks sends the same signal so that $p(\theta)=p\left(\theta \mid d_{2}^{o}\right)$ and $\Delta^{o}\left(d_{2}^{o}, p\left(\theta \mid d_{2}^{o}\right)\right)=$ $\Delta^{o}\left(d_{2}^{o}, p(\theta)\right)=0$ where $d_{2}^{o}=d_{2}^{v}$. In equilibrium it holds that $w\left(d_{2} \geq d_{2}^{v}\right)=t$ and $w\left(d_{2}<\right.$ $\left.d_{2}^{v}\right)=1$. For the various out-of-equilibrium beliefs see the proof of Result 2, p. 23 .

\section{A.7 Proof of Result 5}

According to (5), (6), (11), (12), and with $L P M_{0}(\cdot)>0$ the following relationship holds:

$$
\begin{aligned}
& L P M_{1}\left(\frac{d_{2}^{o} r}{d_{1}}\right)>L \widehat{P} M_{1}\left(\frac{d_{2}^{o} r}{d_{1}}\right) \wedge \operatorname{LPM}_{2}\left(\frac{d_{2}^{o} r}{d_{1}}\right)>L \widehat{P} M_{2}\left(\frac{d_{2}^{o} r}{d_{1}}\right) \\
\Rightarrow \quad \Delta^{m}\left(d_{2}^{o}\right) & <\Delta^{o}\left(d_{2}^{o}, p(\theta)\right)=0
\end{aligned}
$$

$24 \quad L \widehat{P} M_{i}\left(d_{2}^{o *} r / d_{1} \mid d_{2}^{o *}\right)$ symbolises the a posteriori expected Lower Partial Moment $i$ for $R=d_{2}^{o *} r / d_{1}$ whereas $L P M_{i}\left(d_{2}^{o *} r / d_{1} \mid \theta\right)$ equals the Lower Partial Moment $i$ for $R=d_{2}^{o *} r / d_{1}$ if $\theta$ is realised. 


$$
\begin{array}{ll}
\Rightarrow & d_{2}^{m}>d_{2}^{o} \quad \text { where } d_{2}^{m} \text { is defined by } \Delta^{m}\left(d_{2}^{m}\right)=0 \\
\Rightarrow & L P M_{1}\left(\frac{d_{2}^{m} r}{d_{1}}\right)>L P M_{1}\left(\frac{d_{2}^{o} r}{d_{1}}\right) \wedge \quad L P M_{2}\left(\frac{d_{2}^{m} r}{d_{1}}\right)>L P M_{2}\left(\frac{d_{2}^{o} r}{d_{1}}\right) .
\end{array}
$$

Accordingly, for rather low $L P M_{1}\left(d_{2}^{o} r / d_{1}\right)$ and $L P M_{2}\left(d_{2}^{o} r / d_{1}\right)$ it holds

$$
\begin{aligned}
& L P M_{1}\left(\frac{d_{2}^{o} r}{d_{1}}\right)<L \widehat{P} M_{1}\left(\frac{d_{2}^{o} r}{d_{1}}\right) \wedge \quad L P M_{2}\left(\frac{d_{2}^{o} r}{d_{1}}\right)<L \widehat{P} M_{2}\left(\frac{d_{2}^{o} r}{d_{1}}\right) \\
& \Rightarrow \quad L P M_{1}\left(\frac{d_{2}^{m} r}{d_{1}}\right)<L P M_{1}\left(\frac{d_{2}^{o} r}{d_{1}}\right) \wedge \quad L P M_{2}\left(\frac{d_{2}^{m} r}{d_{1}}\right)<L P M_{2}\left(\frac{d_{2}^{o} r}{d_{1}}\right) .
\end{aligned}
$$

\section{A.8 Proof of Result 7}

A pooling equilibrium exists if $L P M_{0}\left(d_{2}^{o} r / d_{1}\right)<1 \forall \theta \in \Theta$ where $d_{2}^{o}$ is defined by $\Delta^{o}\left(d_{2}^{o}, p(\theta)\right)$ $=0$. Because of $\partial L P M_{0}\left(d_{2}^{o} r / d_{1}\right) / \partial d_{2}^{o}=\partial F\left(d_{2}^{o} r / d_{1}\right) / \partial d_{2}^{o}=f\left(d_{2}^{o} r / d_{1}\right) r / d_{1} \geq 0,{ }^{25}$ a pooling equilibrium is the more likely, the lower $d_{2}^{o}$.

a) The less risk averse the depositors, the lower is the required risk premium and hence $d_{2}^{o} \cdot{ }^{26}$

b) From (12) (with $\left.d_{2}=d_{2}^{o}\right), L P M_{0}\left(d_{2}^{o} r / d_{1}\right)>0$,

$$
\begin{aligned}
\frac{\partial \Delta^{o}\left(d_{2}^{o}, p(\theta)\right)}{\partial r}= & -\frac{d_{1}}{r^{2}} u^{\prime}\left(d_{2}^{o}\right) \underbrace{\left[\frac{d_{2}^{o} r}{d_{1}} L \widehat{P} M_{0}\left(\frac{d_{2}^{o} r}{d_{1}}\right)-L \widehat{P} M_{1}\left(\frac{d_{2}^{o} r}{d_{1}}\right)\right]}_{>0} \\
& +\frac{d_{1}{ }^{2}}{r^{3}} u^{\prime \prime}\left(d_{2}^{o}\right) \underbrace{\left[\frac{d_{2}^{o} r}{d_{1}} L \widehat{P} M_{1}\left(\frac{d_{2}^{o} r}{d_{1}}\right)-L \widehat{P} M_{2}\left(\frac{d_{2}^{o} r}{d_{1}}\right)\right]}_{\geq 0}<0,{ }^{27} \text { and } \\
\Delta^{o}\left(d_{2}^{o}, p(\theta)\right)= & \frac{\partial \Delta^{o}\left(d_{2}^{o}, p(\theta)\right)}{\partial d_{2}^{o}} d d_{2}^{o}+\frac{\partial \Delta^{o}\left(d_{2}^{o}, p(\theta)\right)}{\partial r} d r=0
\end{aligned}
$$

follows $d d_{2}^{o} / d r>0$. Besides, it holds that $\partial R^{k} / \partial r=d_{2}^{o} / d_{1}>0$.

c) From $\sum_{\theta \in \Theta} p(\theta)=1$ follows $d p(\bar{\theta})=-\sum_{\theta \neq \bar{\theta}} d p(\theta)$. For analytical convenience let us suppose there exists two possible values of $\theta: \theta_{1}$ and $\bar{\theta}$ with $L P M_{1}\left(d_{2}^{o} r / d_{1} \mid \theta_{1}\right)<L P M_{1}\left(d_{2}^{o} r / d_{1} \mid \bar{\theta}\right)$, and $L P M_{2}\left(d_{2}^{o} r / d_{1} \mid \theta_{1}\right) \leq L P M_{2}\left(d_{2}^{o} r / d_{1} \mid \bar{\theta}\right)$. With $d p(\bar{\theta}) / d p\left(\theta_{1}\right)=-1$ it holds that

$$
\frac{d L \widehat{P} M_{1}\left(\frac{d_{2}^{o} r}{d_{1}}\right)}{d p\left(\theta_{1}\right)}=L P M_{1}\left(\frac{d_{2}^{o} r}{d_{1}} \mid \theta_{1}\right)-L P M_{1}\left(\frac{d_{2}^{o} r}{d_{1}} \mid \bar{\theta}\right)<0
$$

\footnotetext{
$25 f(R)$ is the density function of $R$ with $0 \leq f R)<1$ for $R \in[0, \bar{R}]$.

26 For the implications of depositors' risk aversion see also the proof of Result 1, p. 22.

27 Due to $\operatorname{LPM}_{0}\left(R^{k}\right)=F\left(R^{k}\right)>0$ and $f\left(R^{k}\right) \geq 0, L P M_{1}\left(R^{k}\right)$ is strictly increasing and convex in $R=R^{k}$. It follows that $R^{k} F^{[1]}\left(R^{k}\right) \geq 2 F^{[2]}\left(R^{k}\right)$ and thus $R^{k} L P M_{1}\left(R^{k}\right) \geq L P M_{2}\left(R^{k}\right)$. If, however, $L P M_{0}\left(R^{k}\right)=0$, a change of $r$ does not influence $\Delta^{o}\left(d_{2}^{o}, p(\theta)\right)$, which is equal to $u\left(d_{2}^{o}\right)-u\left(d_{1}\right)$.
} 


$$
\frac{d L \widehat{P} M_{2}\left(\frac{d_{2}^{o} r}{d_{1}}\right)}{d p\left(\theta_{1}\right)}=L P M_{2}\left(\frac{d_{2}^{o} r}{d_{1}} \mid \theta_{1}\right)-L P M_{2}\left(\frac{d_{2}^{o} r}{d_{1}} \mid \bar{\theta}\right) \leq 0
$$

If $p\left(\theta_{1}\right)$ increases, $L \widehat{P} M_{1}(\cdot)$ and possibly $L \widehat{P} M_{2}(\cdot)$ decrease so that $\Delta^{o}\left(d_{2}^{o}, p(\theta)\right)$ rises and $d_{2}^{o}$ is reduced according to (12).

d) If a pooling equilibrium does not exist, $L P M_{0}\left(d_{2}^{o} r / d_{1}\right)<1$ is not fullfilled by types of banks with rather low $L P M_{1}\left(d_{2}^{o} r / d_{1}\right)$, i. e. $L P M_{1}\left(d_{2}^{o} r / d_{1}\right)$ which are lower than $L \widehat{P} M_{1}\left(d_{2}^{o} r / d_{1}\right) .{ }^{28}$ The difference between the possible values of $L P M_{1}(\cdot)$ - for a given target - decreases if low (high) values of $L P M_{1}(\cdot)$ increase (decrease). If we again take to possible values of $\theta, \theta_{1}<\bar{\theta}$, it holds that $d L P M_{i}\left(d_{2}^{o} r / d_{1} \mid \bar{\theta}\right)=-\left(p\left(\theta_{1}\right) / p(\bar{\theta})\right) d L P M_{i}\left(d_{2}^{o} r / d_{1} \mid \theta_{1}\right), i=1,2$. If the difference $L P M_{i}\left(d_{2}^{o} r / d_{1} \mid \bar{\theta}\right)-L P M_{i}\left(d_{2}^{o} r / d_{1} \mid \theta_{1}\right)$ should be reduced, holding $L \widehat{P} M_{i}\left(d_{2}^{o} r / d_{1}\right)$ constant, $L P M_{i}\left(d_{2}^{o} r / d_{1} \mid \theta_{1}\right), i=1,2$, must increase. If $L P M_{1}\left(d_{2}^{o} r / d_{1} \mid \theta_{1}\right)$ is sufficiently high, $L P M_{0}\left(d_{2}^{o} r / d_{1} \mid \theta_{1}\right)<1$ so that a pooling equilibrium exists.

\section{A.9 Proof of Result 8}

With no risk reporting the ex ante expected shortfall and target semivariance are defined as $L \widehat{P} M_{i}\left(d_{2}^{o} r / d_{1}\right)=\sum_{\theta \in \Theta} p(\theta) L P M_{i}\left(d_{2}^{o} r / d_{1} \mid \theta\right), i=1,2$, in case of a pooling equilibrium. With risk reporting they are defined as $\sum_{\theta \in \Theta} p(\theta) L P M_{i}\left(d_{2}^{m}(\theta) r / d_{1} \mid \theta\right), i=1,2 .{ }^{29}$ Let $\tilde{\theta} \in \Theta$ be defined by $d_{2}^{m}(\theta) \leq d_{2}^{o}$ for $\theta \leq \tilde{\theta}$ and $d_{2}^{m}(\theta)>d_{2}^{o}$ for $\theta>\tilde{\theta}$. A bank's risk exposure with risk reporting is ex ante higher than without risk reporting if

$$
\begin{aligned}
& \sum_{\theta \in \Theta} p(\theta)\left[L P M_{i}\left(\frac{d_{2}^{m}(\theta) r}{d_{1}} \mid \theta\right)-L P M_{i}\left(\frac{d_{2}^{o} r}{d_{1}} \mid \theta\right)\right]>0 \\
\Leftrightarrow & \sum_{\theta \leq \tilde{\theta}} p(\theta) \underbrace{\left[L P M_{i}\left(\frac{d_{2}^{m}(\theta) r}{d_{1}} \mid \theta\right)-L P M_{i}\left(\frac{d_{2}^{o} r}{d_{1}} \mid \theta\right)\right]}_{\leq 0 \text { because } d_{2}^{m}(\theta) \leq d_{2}^{o}} \\
+ & \sum_{\theta>\tilde{\theta}} p(\theta) \underbrace{\left[L P M_{i}\left(\frac{d_{2}^{m}(\theta) r}{d_{1}} \mid \theta\right)-L P M_{i}\left(\frac{d_{2}^{o} r}{d_{1}} \mid \theta\right)\right]}_{>0 \text { because } d_{2}^{m}(\theta)>d_{2}^{o}}>0, \quad i=1,2 .
\end{aligned}
$$

It is more likely that this inequality is fulfilled, a) if $p(\theta)$ with $\theta>\tilde{\theta}$ is high (and accordingly $p(\theta)$ with $\theta \leq \tilde{\theta}$ is very small), b) if the difference in the last brackets is high and the absolute value of the difference in the first brackets is small.

\footnotetext{
28 See proof of Result 3, p. 24.

29 Here we use $d_{2}^{m}(\theta)$ instead of $d_{2}^{m}$ to emphasise that $d_{2}^{m}$ depends on the realised and published values of $L P M_{1}\left(R^{k}\right)$ und $L P M_{2}\left(R^{k}\right)$ and thus on the value of $\theta$ whereas $d_{2}^{o}$ is the same for all $\theta$.
} 


\section{References}

Allen, F. and Gale, D., 1998, Optimal financial crises. Journal of Finance, 53, 1245-1284.

Alonso, I., 1996, On avoiding bank runs. Journal of Monetary Economics, 39, 73-87.

Boonprakaikawe, J. and Ghosal, S., 2001, Bank runs and noisy signals. CSGR Working Paper 70/01, CSGR.

Bougheas, S., 1999, Contagious bank runs. International Review of Economics and Finance, 8, 131-146.

Calomiris, C. W. and Kahn, C. M., 1991, The role of demandable debt in structuring optimal banking arrangements. American Economic Review, 81, 497-513.

Carletti, E., 1999, Bank moral hazard and market discipline. Discussion paper 326, LSE Financial Markets Group, London.

Chari, V. V. and Jagannathan, R., 1988, Banking panics, information, and rational expectations equilibrium. Journal of Finance, 43, 749-761.

Chen, Y., 1994, The Role of Information Externalities in Bank Runs. Ph.D. thesis, University of California, Los Angeles.

Chen, Y., 1999, Banking panics: The role of the first-come, first-served rule and information externalities. Journal of Political Economy, 107, 946-968.

Cordella, T. and Levy Yeyati, E., 1998, Public disclosure and bank failures. IMF Staff Papers, 45, 110-131.

Dasgupta, A., 2001, Financial contagion through capital connections: A model of the origin and spread of bank panics. Working paper, Yale University, Northwestern University.

Diamond, D. W. and Dybvig, P. H., 1983, Bank runs, deposit insurance, and liquidity. Journal of Political Economy, 91, 401-419.

Dowd, K., 1992, Models of banking instability: A partial review of the literature. Journal of Economic Surveys, 6, 107-132.

Drehmann, M., 2002, Will an optimal deposit insurance always increase financial stability? Working paper, Universität Bonn.

Fudenberg, D. and Tirole, J., 1991, Game Theory. MIT Press, Cambridge, Mass., London. 
Goldstein, I. and Pauzner, A., 2002, Demand deposit contracts and the probability of bank runs. Working paper, Duke University, Tel Aviv University.

Gorton, G., 1985, Bank suspension of convertibility. Journal of Monetary Economics, 15, $177-193$.

Gorton, G. and Pennacchi, G., 1990, Financial intermediaries and liquidity creation. Journal of Finance, 45, 49-71.

Harsanyi, J. C., 1967/8, Games with incomplete information played by "Bayesian" players. Management Science, 14, 159-182, 320-334, 486-502.

Hellwig, M., 1994, Liquidity provision, banking, and the allocation of interest rate risk. European Economic Journal, 38, 1363-1389.

Hirshleifer, J., 1971, The private and social value of information and the reward to inventive activity. American Economic Review, 61, 561-574.

Jacklin, C. J., 1989, Demand equity and deposit insurance. Research Paper 1062, Graduate School of Business, Stanford University.

Jacklin, C. J., 1993, Market rate versus fixed rate demand deposits. Journal of Monetary Economics, 32, 237-258.

Jacklin, C. J. and Bhattacharya, S., 1988, Distinguishing panics and information-based bank runs: Welfare and policy implications. Journal of Political Economy, 96, 568-592.

Linsmeier, T. J., Thornton, D. B., Venkatachalam, M., and Welker, M., 2000, Do SEC disclosures reduce investors' disagreements about firms' exposures to market risk?: A trading volume analysis. Working Paper 2000-13, Queen's University, Kingston.

Loewy, M. B., 1998, Information-based bank runs in a monetary economy. Journal of Macroeconomics, 20, 681-702.

Rajgopal, S., 1999, Early evidence on the informativeness of the SEC's market risk disclosures: The case of commodity price risk exposure of oil and gas producers. Accounting Review, 74, 251-280.

Rajgopal, S. and Venkatachalam, M., 1999, Are earnings sensitivity measures risk-relevant? The case of oil price risk for the petroleum refining industry. Working paper, Stanford University, Stanford.

Rasmusen, E., 2001, Games and Information - An Introduction to Game Theory. Blackwell, Malden, Mass., Oxford, 3 edition. 
Rochet, J.-C. and Vives, X., 2002, Coordination failures and the lender of last resort: Was Bagehot right after all? HWWA Discussion Paper 184, Hamburgisches Welt-WirtschaftsArchiv (HWWA), Hamburg.

Thornton, D. B. and Welker, M., 2000, Impact of mandated market risk disclosures on investor-perceived exposure to commodity prices: The case of oil and gas producers. Working Paper 00-11, Queen's University, Kingston.

Wolf, J., 1999, Depositenverträge, Einlagensicherung und die Vermeidung von Bank Runs. LIT, Münster. 
Figure 1: Time Structure

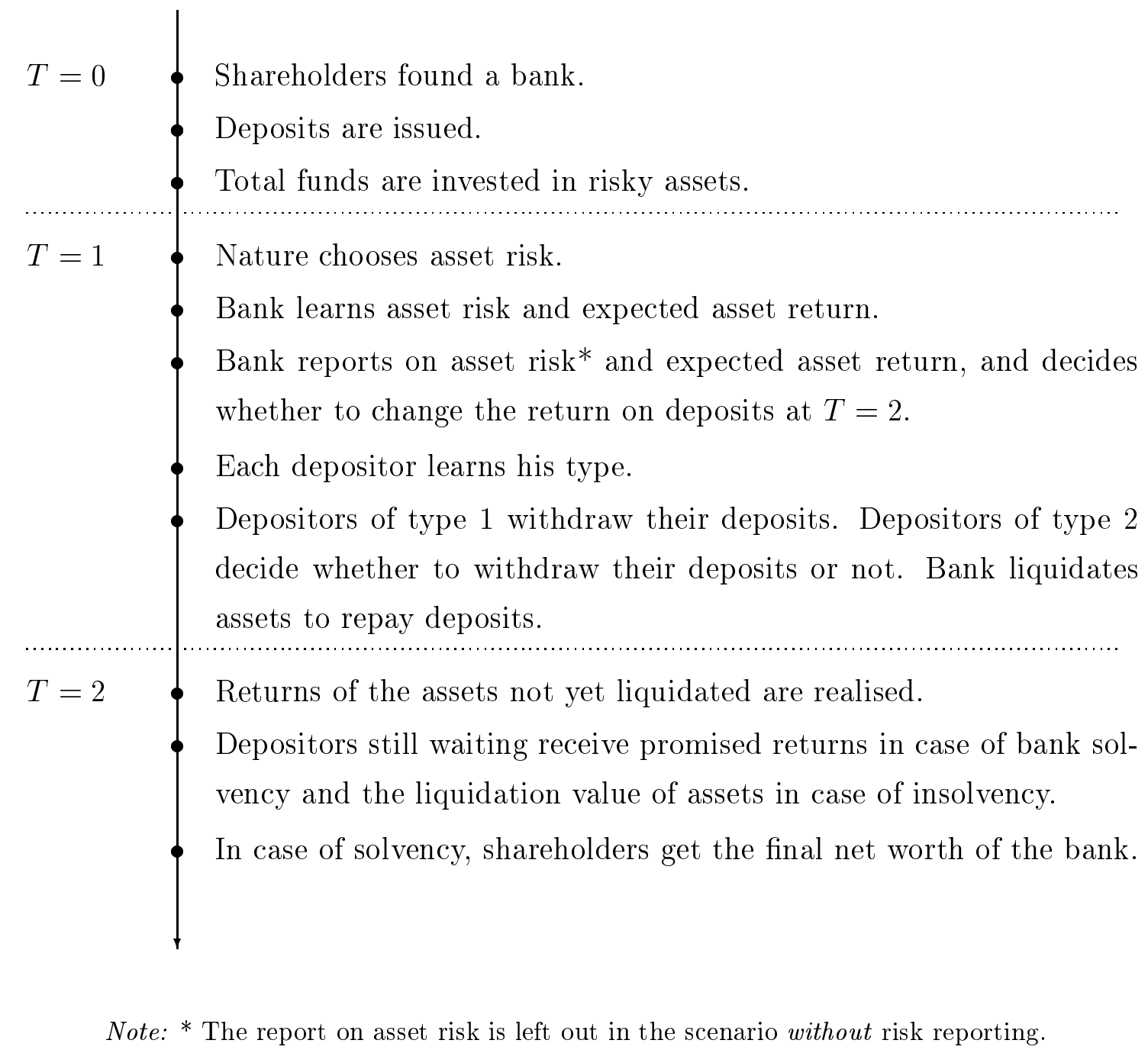


Figure 2: Scenario with Pooling Equilibria

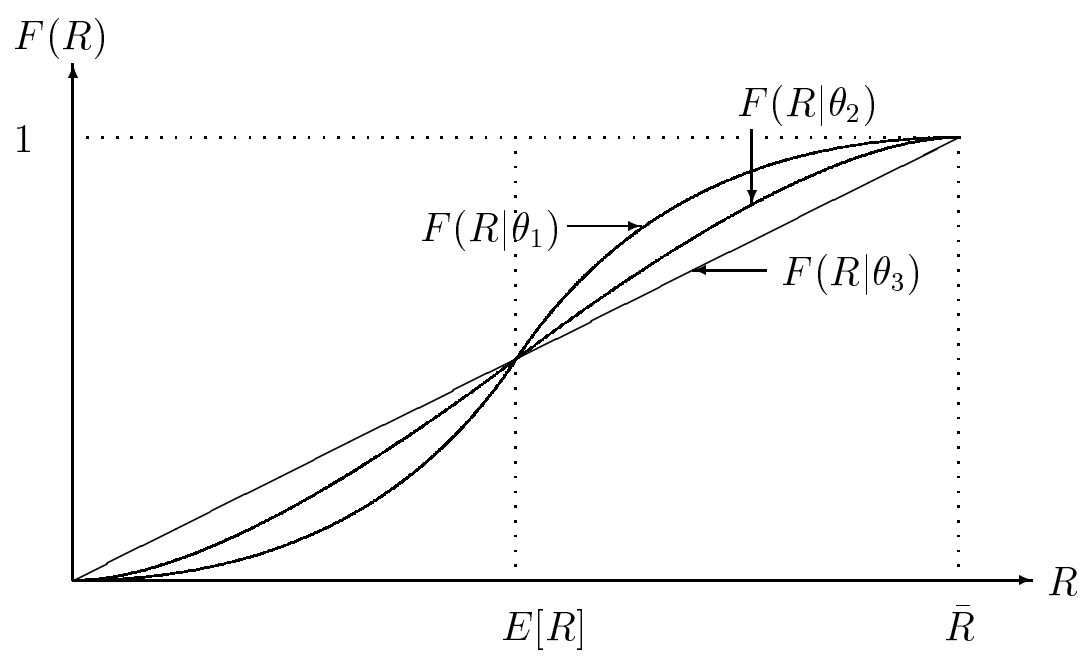

Table 1: Example of Pooling Equilibria

\begin{tabular}{|l|rrr|}
\hline Types of banks & 1 & 2 & 3 \\
\hline \hline$\theta$ & 0.5 & 1 & 2.4 \\
\hline$p(\theta)=p\left(\theta \mid d_{2}^{o}\right)$ & 0.4 & 0.3 & 0.3 \\
\hline$d_{2}^{o}$ & \multicolumn{3}{|c|}{$\mathbf{1 . 2 6 2 9}$} \\
\hline$E\left[V\left(d_{2}^{o}, t\right)\right]$ & 4.0106 & 6.7013 & 14.3667 \\
\hline$L P M_{1}\left(R^{k}\right)$ & 0.0392 & 0.1004 & 0.2746 \\
\hline$L P M_{2}\left(R^{k}\right)$ & 0.0052 & 0.0300 & 0.2102 \\
\hline
\end{tabular}

Note: $R$ is uniformly distributed over $[E[R]-0.5 \theta, E(R)+0.5 \theta] ; E[R]=1.2 ; \bar{R}=2.4 ; r=1$; $d_{1}=1.1 ; D=100 ; C=10 ; t=0.6 ; u\left(d_{i}\right)=-2 d_{i}{ }^{2}+10.824 d_{i}, i=1,2$. According to their prior beliefs, the depositors decide to wait if all types of banks promise to pay $d_{2}^{o}=1.2629$ in $T=2$. Since the expected final net worth, $E\left[V\left(d_{2}^{o}, t\right)\right]$, is positive for each type, all types send the same signal offering $d_{2}^{o}$ so that $p\left(\theta \mid d_{2}^{o}\right)=p(\theta)$. Depositors' posterior beliefs equal their prior beliefs. 
Table 2: Example of Partial Pooling

\begin{tabular}{|l|rrr|rr|}
\hline Types of banks & 1 & 2 & 3 & 2 & 3 \\
\hline \hline$\theta$ & 0.5 & 1 & 2.4 & 1 & 2.4 \\
\hline$p(\theta)$ & 0.05 & 0.25 & 0.7 & & \\
\hline$p\left(\theta \mid d_{2}^{o *}\right)$ & & & & 0.2632 & 0.7368 \\
\hline$d_{2}^{o(*)}$ & & 1.6128 & & \multicolumn{2}{|c|}{$\mathbf{1 . 6 5 9 0}$} \\
\hline$E\left[V\left(d_{2}^{o(*)}, t\right)\right]$ & $\mathbf{0}$ & 1.2029 & 7.9938 & 0.8095 & 7.2906 \\
\hline$L P M_{1}\left(R^{k}\right)$ & 0.2662 & 0.2935 & 0.4478 & 0.3266 & 0.4739 \\
\hline$L P M_{2}\left(R^{k}\right)$ & 0.0917 & 0.1499 & 0.4377 & 0.1760 & 0.4765 \\
\hline
\end{tabular}

Note: $R$ is uniformly distributed over $[E[R]-0.5 \theta, E(R)+0.5 \theta] ; E[R]=1.2 ; \bar{R}=2.4 ; r=1$; $d_{1}=1.1 ; d_{2}^{v}<1.6128 ; D=100 ; C=10 ; t=0.6 ; u\left(d_{i}\right)=-2 d_{i}{ }^{2}+10.824 d_{i}, i=1,2$. In the central column we find the data based on the a priori probabilities, $p(\theta)$. The depositors would wait until $T=2$ if all types of banks offered $d_{2}^{o}=1.6128$. As the expected final net worth of type $1, E\left[V\left(d_{2}^{o}, t\right)\right]$, would be equal to zero, type 1 does not offer $d_{2}^{o}$. Based on the a posteriori probabilities, $p\left(\theta_{1} \mid d_{2}^{o *}\right)=0, p\left(\theta_{2} \mid d_{2}^{o *}\right)=0.25 / 0.95=0.2632$ and $p\left(\theta_{3} \mid d_{2}^{o *}\right)=0.7 / 0.95=0.7368$ (see right column), the critical return is $d_{2}^{o *}=1.6590$. Type 2 and 3 offer this return because their expected final net worth, $E\left[V\left(d_{2}^{o *}, t\right)\right]$, is still positive. 
Table 3: Example of Lemon Equilibria

\begin{tabular}{|l|rrrr|rr|r|}
\hline Types of banks & 1 & 2 & 3 & 2 & 3 & 3 \\
\hline \hline$\theta$ & 0.5 & 1 & 2.4 & 1 & 2.4 & 2.4 \\
\hline$p(\theta)$ & 0.05 & 0.05 & 0.9 & & & \\
\hline$p\left(\theta \mid d_{2}^{o(*)}\right)$ & & & & 0.0526 & 0.9474 & 1 \\
\hline$d_{2}^{o(*)}$ & & 1.8434 & & 1.9173 & $\mathbf{1 . 9 7 7 0}$ \\
\hline$E\left[V\left(d_{2}^{o(*)}, t\right)\right]$ & 0 & 0.0129 & 4.8074 & 0 & 3.9568 & 3.1322 \\
\hline$L P M_{1}\left(R^{k}\right)$ & 0.4758 & 0.4761 & 0.5851 & 0.5430 & 0.6329 & 0.6866 \\
\hline$L P M_{2}\left(R^{k}\right)$ & 0.2472 & 0.3097 & 0.6537 & 0.3782 & 0.7355 & 0.8310 \\
\hline
\end{tabular}

Note: $R$ is uniformly distributed over $[E[R]-0.5 \theta, E(R)+0.5 \theta] ; E[R]=1.2 ; \bar{R}=2.4 ; r=1$; $d_{1}=1.1 ; d_{2}^{v}<1.8434 ; D=100 ; C=10 ; t=0.6 ; u\left(d_{i}\right)=-2 d_{i}{ }^{2}+10.824 d_{i}, i=1,2$. In the second column we find the data based on the a priori probabilities, $p(\theta)$. The depositors would wait until $T=2$ if all types of banks offered $d_{2}^{o}=1.8434$. As the expected final net worth of type $1, E\left[V\left(d_{2}^{o}, t\right)\right]$, would be equal to zero, type 1 does not offer $d_{2}^{o}$. Based on the a posteriori probabilities in the third column the critical return would be 1.9173 , which, however, would not be offered by type 2 because its expected final net worth would be equal to zero as well. In equilibrium (see forth column) it holds that $p\left(\theta_{1} \mid d_{2}^{o *}\right)=p\left(\theta_{2} \mid d_{2}^{o *}\right)=0, p\left(\theta_{3} \mid d_{2}^{o *}\right)=1$ and $d_{2}^{o *}=1.9770$.

Table 4: Equilibria in the Game between Bank and Depositors without Risk Reporting

\begin{tabular}{|c|c|c|}
\hline \multirow[b]{2}{*}{ Critical return $d_{2}^{o}$} & \multicolumn{2}{|c|}{ Expected final net worth of the bank, $E\left[V\left(d_{2}^{o}, t\right)\right]$, } \\
\hline & for each type positive & only for some types positive \\
\hline$<d_{2}^{v}$ & \multirow{3}{*}{ pooling equilib } & $\begin{array}{l}\text { partial pooling or lemon } \\
\text { equilibrium (Result } 3 \text { ) if } \\
\qquad d_{2}^{o *} \neq d_{2}^{v}\end{array}$ \\
\hline$=d_{2}^{v}$ & & (Results 2 and 4$)$ \\
\hline$>d_{2}^{v}$ & & $\begin{array}{l}\text { partial pooling or lemon } \\
\text { equilibrium (Result } 3 \text { ) }\end{array}$ \\
\hline
\end{tabular}

Note: $d_{2}^{o}$ symbolises the return on deposits that is based on the depositors' prior beliefs and is just high enough to prevent a bank run at $T=1$. It is implicitly defined by $\Delta^{o}\left(d_{2}^{o}, p(\theta)\right)=0$. $d_{2}^{v}$ represents the return on deposits initially agreed upon whereas $d_{2}^{o *}$ stands for the return on deposits in equilibrium. $d_{2}^{o *}$ is implicitly defined by $\Delta^{o}\left(d_{2}^{o *}, p\left(\theta \mid d_{2}^{o *}\right)\right)=0$. From $d_{2}^{o}>d_{2}^{v}$ (together with $d_{2}^{o *}>d_{2}^{o}$ ) it follows that $d_{2}^{o *}>d_{2}^{v}$. Therefore, the condition $d_{2}^{o *} \neq d_{2}^{v}$ is fulfilled in the last row of the table. 